This item was submitted to Loughborough's Research Repository by the author.

Items in Figshare are protected by copyright, with all rights reserved, unless otherwise indicated.

\title{
Transient mixed non-Newtonian thermo-elastohydrodynamics of vehicle differential hypoid gears with starved partial counter-flow inlet boundary
}

PLEASE CITE THE PUBLISHED VERSION

http://dx.doi.org/10.1177/1350650114537805

PUBLISHER

Sage Publications ( IMechE

VERSION

AM (Accepted Manuscript)

LICENCE

CC BY-NC-ND 4.0

\section{REPOSITORY RECORD}

Mohammadpour, Mahdi, Stephanos Theodossiades, and Homer Rahnejat. 2019. "Transient Mixed Nonnewtonian Thermo-elastohydrodynamics of Vehicle Differential Hypoid Gears with Starved Partial Counterflow Inlet Boundary". figshare. https://hdl.handle.net/2134/15067. 
This item was submitted to Loughborough's Institutional Repository (https://dspace.lboro.ac.uk/) by the author and is made available under the following Creative Commons Licence conditions.

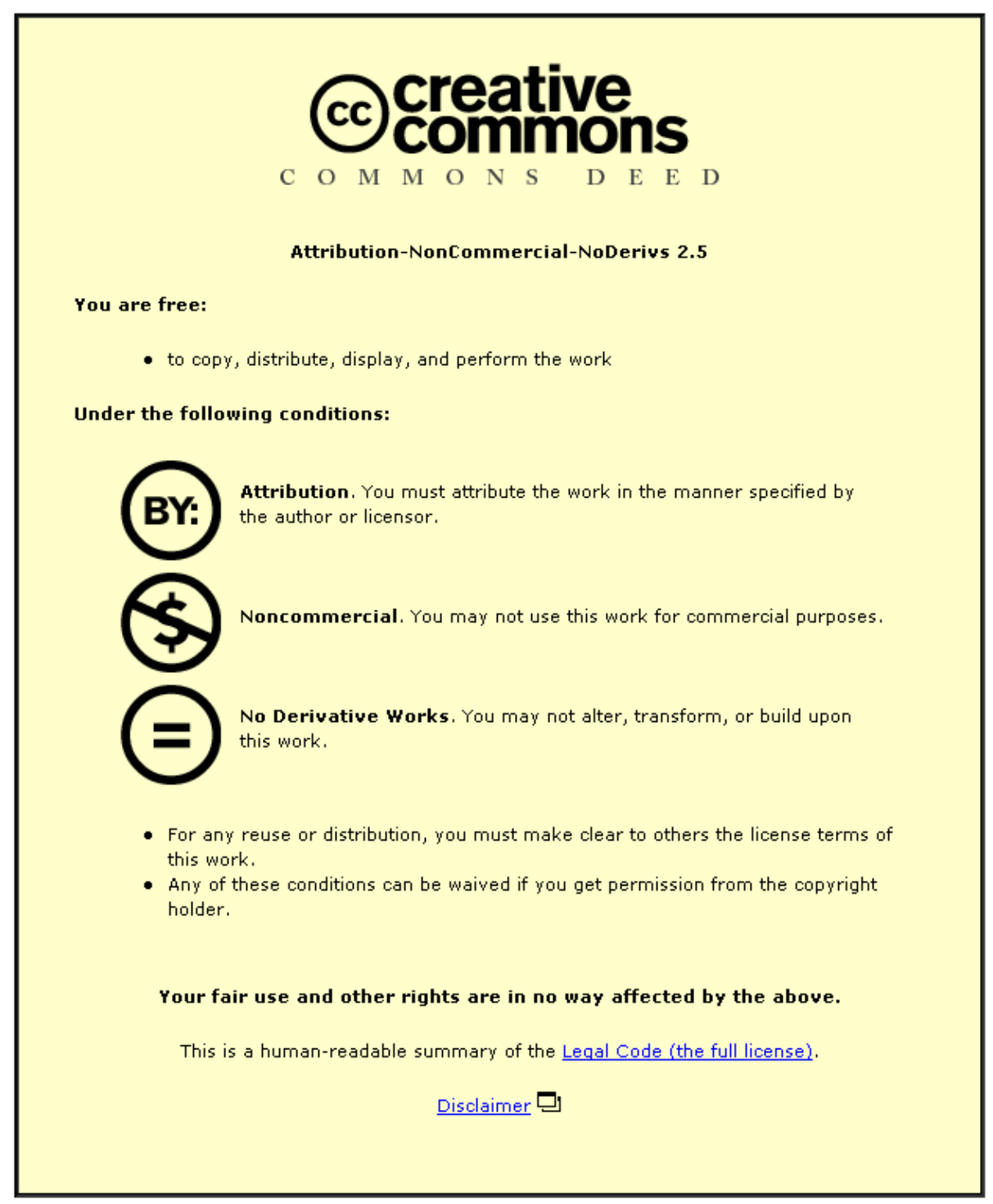

For the full text of this licence, please go to: http://creativecommons.org/licenses/by-nc-nd/2.5/ 


\title{
Transient mixed non-Newtonian thermo-elastohydrodynamics of vehicle differential hypoid gears with starved partial counter-flow inlet boundary
}

\author{
Mahdi Mohammadpour ${ }^{1}$, Stephanos Theodossiades ${ }^{1}$ and Homer Rahnejat ${ }^{1} *$ \\ 1) Wolfson School of Mechanical and Manufacturing Engineering, Loughborough University, \\ Loughborough, UK \\ *Corresponding author: h.rahnejat@lboro.ac.uk
}

\begin{abstract}
The paper presents solutions for transient mixed thermo-elastohydrodynamics of meshing differential hypoid gears of a vehicle under low speed urban driving and high speed cruising. Realistic gear meshing conditions, such as contact load including inertial effects are used, in line with engine power torque and wheel traction. This constitutes simultaneous solution of gear pair dynamics, non-Newtonian elastohydrodynamics as well as vehicle longitudinal inertial dynamics, an approach not hitherto reported in literature. The important link between contact tribology and vehicle gearing dynamics is highlighted. It is also shown that gear teeth pairs are subjected to a starved inlet boundary condition, represented by realistic inlet flow analysis. These conditions lead to the formation of a thin lubricant film with non-Newtonian shear and with modest boundary interactions.
\end{abstract}

\section{Keywords: vehicle differential, hypoid gears, dynamic transmission error,}

elastohydrodynamic lubrication, zero reverse flow inlet boundary, starvation, non-

\section{Newtonian shear}

\section{Introduction}

Improved transmission efficiency is a key design target for differential hypoid gears. This depends mainly on the operating temperature and contact conditions of pairs of meshing teeth of the pinion and the ring gear under realistic vehicle running conditions. The important objective is to ascertain the parasitic frictional losses. Additionally, powertrain Noise, Vibration and Harshness (NVH) refinement is increasingly another important area of concern, often represented by the dynamic transmission error. Therefore, a tribo-dynamic analysis is required to take into account the interactions between system dynamics (gearing and vehicle tractive condition) and contact mechanics of meshing pairs [1].

Various research workers have investigated the dynamics of non-parallel axes gears, such as hypoid and bevel gears [2-5]. Elastohydrodynamic regime of lubrication is prevalent in hypoid gear pairs. Some recent analyses include those reported by Mohammadpour et al [6, 
7]. Due to the complexity of gear geometry, data required for elastohydrodynamic analysis should be obtained using Tooth Contact Analysis (TCA) [8]. However, quasi-static analyses described in many contributions, including in $[6,7]$, neglect the gear dynamic behaviour, as $\underline{\text { well as realistic inertial loading emanating from vehicle tractive motion. Recently the effects }}$ of elastohydrodynamic contact condition on the dynamics of geared systems have been studied by Li-and Kahraman [9-11]. Their results for both dynamically and quasi-statically loaded high speed spur gears showed the importance of dynamic loading on the lubrication of geared systems. They incorporated the shear stress distribution along the contact surface to formulate the viscous damping effect of the gear meshing process.

In the case of quasi-static analysis, the effect of inertial dynamics is ignored, which is as the result of vehicle motion, including aerodynamic loading and tyre-road traction. Furthermore, often the transient contact behaviour is not retained. These play an important role in the linkage between the inertial dynamics and contact conditions, such as generated friction and vibration. Additionally, contact stiffness and damping are functions of the regime of lubrication. The effective contact stiffness is as the result of a combination of presence of a lubricant film and any elastic deformation of adjacent elastic contacting solid boundaries [12, 13]. Since these stiffness contributions may be regarded as acting in series, then the effective contact stiffness is the addition of their reciprocals. Hence, the effective stiffness is dominated by the lower of the two contributions. For light-to-moderately loaded conjunctions the stiffness of the lubricant film is dominant, such as under hydrodynamic conditions, where the lubricant is still compressible. One example of $\mathrm{NVH}$ with dominant lubricant stiffness is transmission rattle $[14,15]$. However, in highly loaded concentrated contacts such as meshing of hypoid gears, the regime of lubrication is often elastohydrodynamic with incompressible state of the lubricant. Thus, the stiffness of the elastic solid boundaries is the prevailing contribution to the effective contact stiffness (this is often very closely approximated by the Hertzian condition, especially with thin films, often subjected to non-Newtonian shear). The amorphous nature of the lubricant under the elastohydrodynamic regime of lubrication presents insignificant damping even with squeeze film motion [16, 17]. Any attenuation due to lubricant action is achieved through friction acting as an energy sink (as also noted in 911). There can also be some hysteretic material damping from localised deflection of the contiguous surfaces [18].

A difficulty in combining system dynamics with elastohydrodynamic analysis of a number of simultaneous meshing teeth pairs is the required computation time for the latter in each integration step of the former. This problem was first overcome for the case of tribo-dynamic analysis of an entire ball bearing by Rahnejat and Gohar [19], using extrapolated oil film thickness formulae, regressed from a large number of elastohydrodynamic analyses for given contact configurations and operating conditions. The approach enables simulation of even more complex tribo-dynamic problems, for instance for the entire transmission systems, with the predictions showing good conformance with the full transient solution of elastohydrodynamic contacts [20]. The potential drawbacks are conditions which may emerge, resulting in extrapolation beyond the range of values employed in the derivation of the original oil film thickness equation. Furthermore, these formulae often embody certain 
assumptions, which underlie the original numerical simulations, such as an assumed fully flooded inlet boundary or pure Newtonian shear of the lubricant.

The contact footprint for a pair of hypoid gear teeth is elliptical of long aspect ratio with the lubricant entrainment flow taking place often at an angle to its minor axis. This means that significant side leakage flow can occur which affects the lubricant film thickness. Thorp and Gohar [21] studied the contact footprint and film formation for rolling and sliding elliptical contacts using optical interferometry. Numerical analysis for the same conditions by JalaliVahid et al [22] agreed well with the experimental work in [21] for light to moderate loads, showing angled lubricant flow entrainment into the contact. For such conditions, Chittenden et al [23] provided an extrapolated oil film thickness formula which can be used in a tribodynamic analysis. For the case of hypoid gear pairs, high contact loads and entrainment speed can lead to very thin films subjected to non-Newtonian shear. The thinness of the film is often exacerbated by a starved inlet condition, which has been adjusted by Mohammadpour et al [6] using demarcation boundaries obtained by Hamrock and Dowson [24]. However, more realistic inlet boundary conditions must be established based on potential flow analysis with some proportion of reversing flow at the inlet. This approach was first highlighted by Tipei [25] and recently confirmed by numerical predictions and experimental measurements [26]. It transpires that such a fundamental analysis of inlet flow suggests Swift-Stieber boundary condition rather than one which may be derived through numerical predictions or experimental observations alone. The predictions of the lubricant film thickness should also be corrected when non-Newtonian conditions are encountered [2, 3, 27].

This paper integrates gear pair and vehicle longitudinal dynamics with mixed-thermoelasthydrodynamic contact model of meshing teeth pairs of vehicular differential hypoid gears, an approach not hitherto reported in literature. The non-Newtonian and thermal lubricant shear characteristics as well as asperity interactions under transient dynamic conditions are also taken into account.

A realistic inlet flow entrainment into the teeth pair contact is employed, using potential flow with some reverse counter-flow, as well as non-Newtonian shear characteristics for thin elastohydrodynamic films, based on those reported by Evans and Johnson [28]. According to [29] the effect of generated heat on the film thickness in highly loaded contacts such as in hypoid gears is fairly insignificant. However, thermal effects significantly affect the shear stress and therefore friction characteristics. The current model takes into account the effect of temperature on friction as represented by the formulae in [28], which was obtained using a combined experimental-analytical study of the tractive behaviour of the lubricants under elastohydrodynamic conditions.

The paper demonstrates the inexorable link between system dynamics and tribological performance, which are essential for the evaluation of contact stiffness and damping (both essential for dynamics analysis) and lubricant shear characteristics (important for a tribological analysis), leading to the assessment of parasitic losses. The above represent the main contributions of this paper, as well as the integration of system dynamics and contact 
conditions within the same analysis framework.

\section{Tribological Model}

\section{Lubricated contact}

As described in the Introduction, a suitable extrapolated oil film thickness formula is required to represent the prevailing contact conditions in the meshing of the hypoid gear teeth pairs. For angled flow entrainment to the minor axis of the elliptical contact footprint with lateral side leakage, the formula by Chittenden et al [23] is the most suitable. Therefore, its validity against full numerical solution for the broad range of conditions encountered in the differential hypoid gear pair must be first established.

The form of Reynolds equation for lubricant entrainment at any angle $\theta$ to the minor axis of an elliptical contact footprint is given as (Figure 1):

$\frac{\partial}{\partial x}\left[\frac{\rho h^{3}}{\eta} \frac{\partial p}{\partial x}\right]+\frac{\partial}{\partial y}\left[\frac{\rho h^{3}}{\eta} \frac{\partial p}{\partial y}\right]=6 U\left\{\cos \theta \frac{\partial}{\partial x}[\rho h]+\sin \theta \frac{\partial}{\partial y}[\rho h]\right\}$

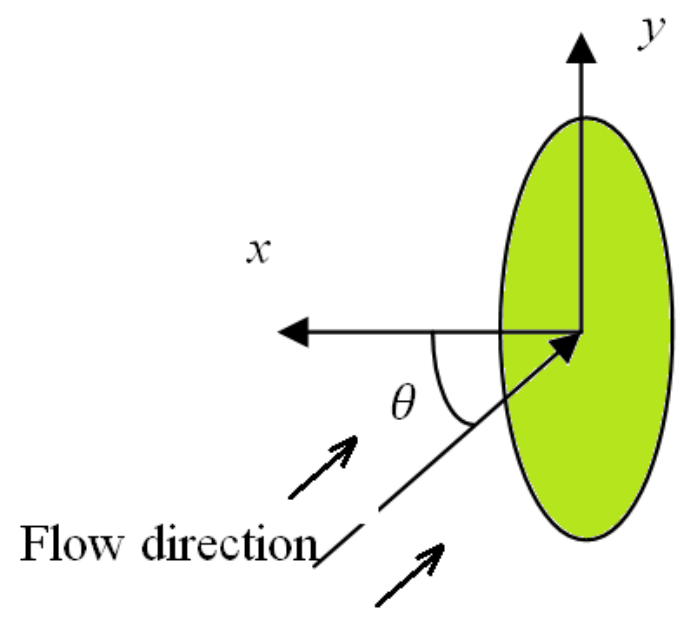

Figure 1: Representation of an elliptical point contact conjunction with angled entrainment flow

Transient effects are included in the analysis through changes in dynamic loads, contact kinematics (rolling and sliding surfaces) and the geometry of contact such as the radii of curvature of mating surfaces. The difference between a quasi-static (usually reported) and dynamic flank loads is shown in the Eesults and discussion section. The form of Reynolds equation (1) omits the effect of squeeze film which occurs as the result of approach and 
separation of gear teeth pairs through mesh. This is a transient effect which often increases the load carrying capacity of the contact as noted by Gohar and Rahnejat [12].

In practice, a non-dimensional form of Reynolds equation is used in finite difference form for the solution of the problem. This non-dimensional form is provided in Appendix A1. The discretised form of the equation using finite differences is also provided there. Central differences are used for the discretisation of the Poiseuille flow terms on the left hand side of the Reynolds equation. Forward, backward and/or central discretization can be used for the right hand side terms; the Couette flow terms.

The film thickness at any spatial location within the contact domain is given by:

$$
h(x, y)=h_{c 0}+s(x, y)+\delta(x, y)
$$

where, the undeformed parabolic conjunctional profile is: $s(x, y)=\frac{x^{2}}{2 R_{z x}}+\frac{y^{2}}{2 R_{z y}}$ $R_{z x}$ and $R_{z y}$ are the equivalent radii of contact of an ellipsoidal solid against a semi-infinite elastic half-space, representing the instantaneous contact of any pinion to gear wheel teeth pair in the planes $z x$ (along the minor axis of the contact ellipse) and $z y$ (along its major axis, figure 2):

$\frac{1}{R_{z x}}=\frac{1}{r_{p}}+\frac{1}{r_{w}}$ and $\frac{1}{R_{z y}}=\frac{1}{R_{w}}-\frac{1}{R_{p}}$

The instantaneous radii of pinion and gear teeth are determined through TCA [5].

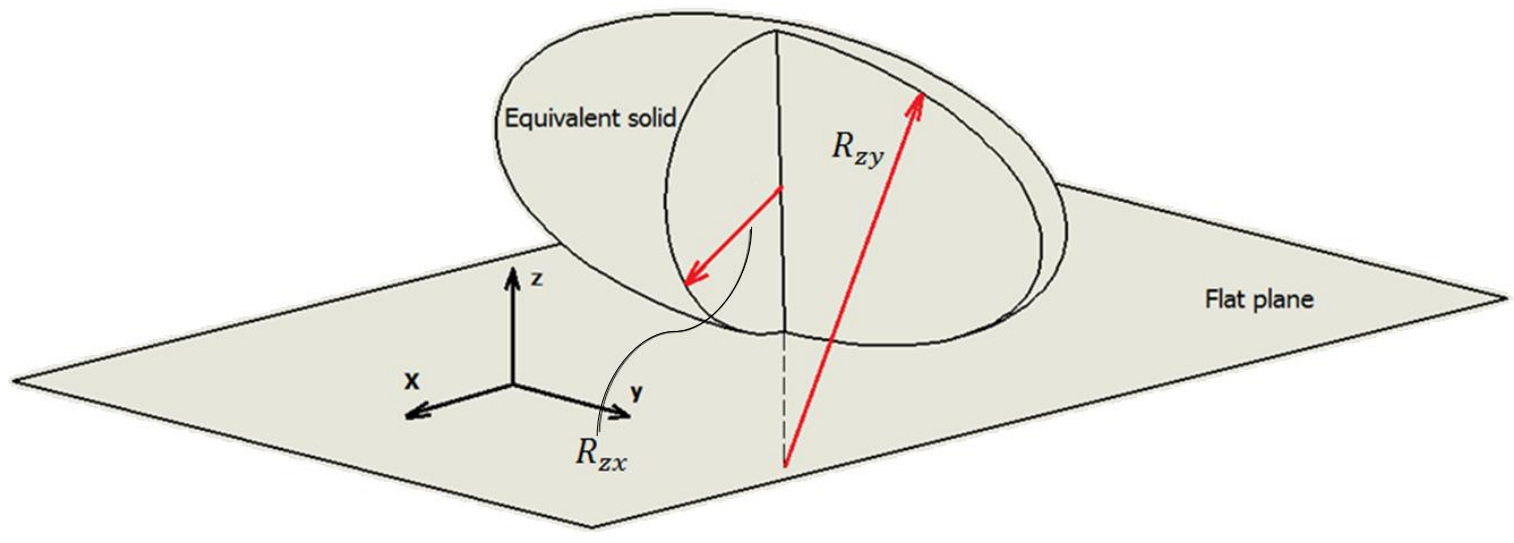

Figure 2: Contact Geometry of the equivalent ellipsoidal solid 
The localised contact deflection $\delta(x, y)$ is obtained using the elasticity potential integral:

$\delta(x, y)=\frac{1}{E_{r}} \iint_{A} \frac{p\left(x_{1}, y_{1}\right) d x_{1} d y_{1}}{\sqrt{\left(x-x_{1}\right)^{2}+\left(y-y_{1}\right)^{2}}}$

where, $(x, y)$ represents a point where deflection of the semi-infinite elastic half-space of reduced elastic modulus $E_{r}$ is calculated due to any arbitrary applied pressure distribution $p\left(x_{1}, y_{1}\right)$.

To obtain a solution to the EHL problem, comprising equations (1)-(4), the lubricant rheological state is required.

\section{Lubricant Rheology}

For piezo-viscous lubricant behaviour [30]:

$\eta=\eta_{0} \exp \left\{\left[\left(\ln \eta_{0}+9.67\right) \times\left(1+5.1 \times 10^{-9} p\right)^{Z}\right]-\left[\ln \eta_{0}+9.67\right]\right\}$

where:

$Z=\frac{\alpha c_{p}}{\left(\ln \eta_{0}+9.67\right)}=\frac{\alpha}{5.1 \times 10^{-9}\left(\ln \eta_{0}+9.67\right)}$, as $c_{p}=1.96 \mathrm{MPa}$

For lubricant density [31]:

$\rho=\rho_{0}\left(1+\frac{0.6 \times 10^{-9} p}{1+1.7 \times 10^{-9} p}\right)$

\section{Boundary Conditions}

It is usual to assume a fully flooded inlet in the numerical analysis of elastohydrodynamic lubrication problems, thus:

$x \rightarrow-\infty, p \rightarrow 0$ and $y \rightarrow-\infty, p \rightarrow 0$

In numerical analyses a distance of 4-5 times the contact footprint semi-half-width is usually chosen in the direction of entraining motion to represent fully flooded conditions [32]. The inlet distance changes with load in both contact directions, $x$ and $y: m=x / b^{\prime}$ or $y / a^{\prime}$.

The outlet boundary conditions usually employed are that of Swift-Stieber: 
$p=\partial p / \partial x=0$ at $x=x_{c}$ and $p=\partial p / \partial y=0$ at $y=y_{c}$

where the film rupture positions, $x_{c}$ and $y_{c}$ are obtained numerically by discarding the negatively generated pressures.

Simultaneous solution of equations (1), (2), (4)-(6) using the inlet and outlet boundary conditions (7) and (8) yields the unknowns; $p, h, \delta, \eta$ and $\rho$. The Reynolds equation is discretised using finite differences and the solution is obtained using effective influence low relaxation Newton-Raphson method with Gauss-Seidel iterations [33].

\section{Verification of Extrapolated oil film thickness Formula}

The validity of the oil film thickness formula presented by Chittenden et al [23], obtained with a series of operating conditions under isothermal analysis, is ascertained against the full numerical solution for the contact conditions usually encountered in hypoid gear pairs:

$h_{c 0}^{*}=4.31 U^{* 0.68} G^{* 0.49} W^{* 0.073}\left\{1-\exp \left[-1.23\left(\frac{R_{s}}{R_{e}}\right)^{2 / 3}\right]\right\}$

where, the prevailing contact conditions are embodied in non-dimensional load, rolling viscosity and materials' parameters:

$W^{*}=\frac{\pi W}{2 E_{r} R_{e}^{2}} \quad U^{*}=\frac{\pi \eta_{0} U}{4 E_{r} R_{e}} \quad G^{*}=\frac{2}{\pi}\left(E_{r} \alpha\right)$ and $h^{*}=\frac{h}{R_{e}}$

and:

$\frac{1}{R_{e}}=\frac{\cos ^{2} \theta}{R_{z x}}+\frac{\sin ^{2} \theta}{R_{z y}}, \frac{1}{R_{s}}=\frac{\sin ^{2} \theta}{R_{z x}}+\frac{\cos ^{2} \theta}{R_{z y}}$

Tables A1-A3 in Appendix A2 provide the vehicle, differential gearing and lubricant parameters. Two different vehicle speeds, one at $20 \mathrm{Km} / \mathrm{h}$ (crawling in congested traffic) and the other at $120 \mathrm{Km} / \mathrm{h}$ (highway cruising) are used to ascertain the validity of Chittenden's extrapolated oil film thickness equation against full numerical analysis, both with assumed fully flooded inlet conditions. Figure 3 shows the percentage difference in central lubricant film thickness between the full Reynolds solution and the extrapolated equation. The extrapolated film thickness equation predicts a film thickness on average $17 \%$ higher than the full numerical solution. The main reason for this is that Chittenden et al [23] film thickness 
formula is regressed for elliptical point contacts with an aspect ratio below 3, whereas the hypoid gear pair contact footprint has an aspect ratio around 7-10 most of the time during the meshing cycle. Furthermore, the validity of Chittenden's equation reduces with an increasing contact load for the cases investigated here. The discrepancy is however quite acceptable, particularly that the use of the equation instead of the full solution makes for acceptable computation times as already described above.

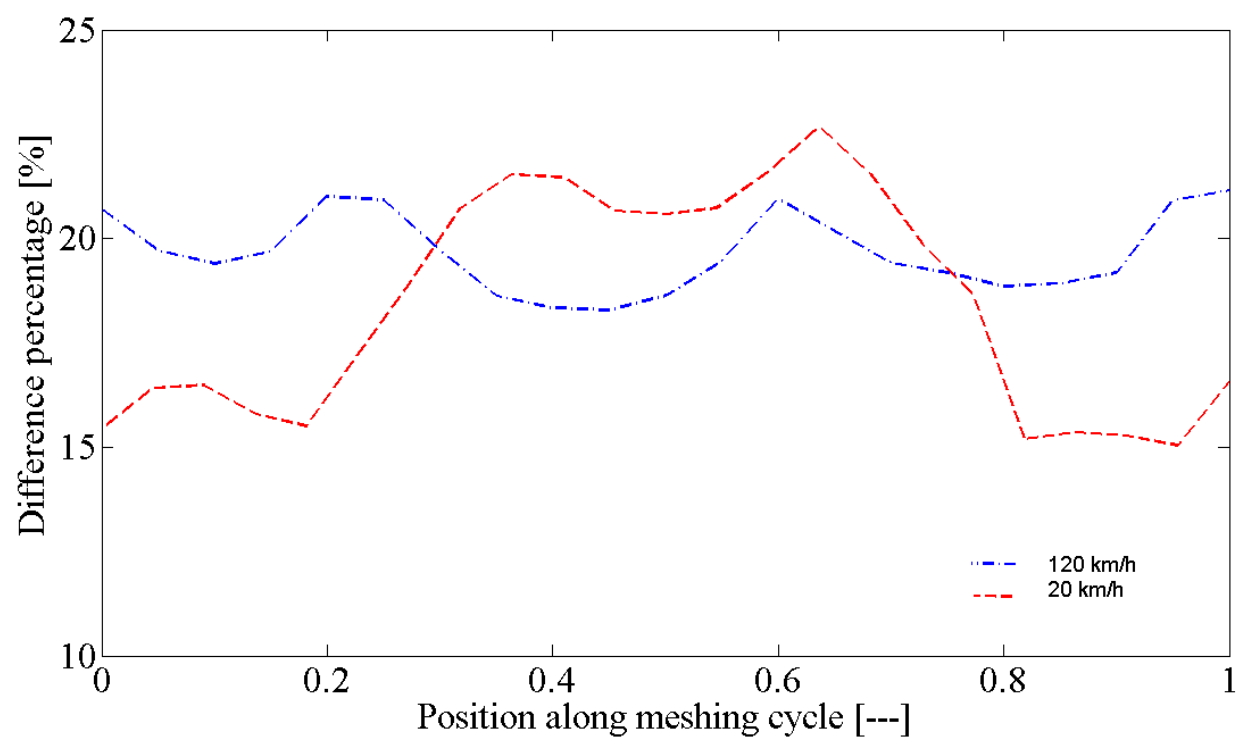

Figure 3: Percentage difference between full EHL solution and Chittenden et al [23] extrapolated oil film thickness equation

\section{Mixed regime of lubrication}

For boundary friction calculations, the Greenwood and Tripp [34] method is used. The method assumes Gaussian distribution of asperities. A proportion of load is carried by the asperities on the opposing contacting surfaces, when mixed or boundary regimes of lubrication are encountered, based on the Stribeck's oil film parameter: $\lambda=\frac{h_{c 0}}{\sigma} \leq 3$, where $\sigma$ is the root mean square composite surface roughness. Usually, a very small proportion of load is carried by the asperities protruding through an insufficiently thick film. The elastohydrodynamic load carrying capacity is:

$W_{h}=\iint_{A} p d x d y$ 
The share of contact load carried by the asperities is [34]:

$W_{a}=\frac{16 \sqrt{2}}{15} \pi(\xi \beta \sigma)^{2} \sqrt{\frac{\sigma}{\beta}} E^{\prime} A F_{5 / 2}(\lambda)$

where, the statistical function $F_{5 / 2}(\lambda)$ for a Gaussian distribution of asperities becomes [1]:

$F_{5 / 2}(\lambda)=\left\{\begin{array}{rr}-0.004 \lambda^{5}+0.057 \lambda^{4}-0.296 \lambda^{3}+0.784 \lambda^{2}-1.078 \lambda+0.617 ; & \text { for } \lambda \leq 3 \\ 0 & ; \text { for } \lambda>3\end{array}\right.$

Usually the roughness parameter $(\xi \beta \sigma)$ is in the range $0.03-0.07$ for steel surfaces. The ratio $\sigma / \beta$ is a representation of the average asperity slope, which is in the range $10^{-4}-10^{-2}[35]$. In the current study it is assumed that $\xi \beta \sigma=0.055$ and $\sigma / \beta=10^{-3}$.

Therefore, the total contact reaction becomes:

$W=W_{h}+W_{a}$

In mixed or boundary regimes of lubrication, asperity friction should be taken into account. There is a thin adsorbed film at the summit of asperities or entrapped in their contact. This thin adsorbed film is subjected to non-Newtonian shear, thus [35]:

$f_{b}=\tau_{L} A_{a}$

where, $\tau_{L}$ is the lubricant's limiting shear stress [36]:

$\tau_{L}=\tau_{0}+\varepsilon P_{m}$

where, $P_{m}=\frac{W_{a}}{A_{a}}$.

The asperity contact area is obtained as [34]:

$A_{a}=\pi^{2}(\xi \beta \sigma)^{2} A F_{2}(\lambda)$

The statistical function $F_{2}(\lambda)$ employed in the equation above is expressed as follows [35]: 


$$
F_{2}(\lambda)=\left\{\begin{array}{rr}
-0.002 \lambda^{5}+0.028 \lambda^{4}-0.173 \lambda^{3}+0.526 \lambda^{2}-0.804 \lambda+0.500 ; & \text { for } \lambda \leq 3 \\
0 & ; \text { for } \lambda>3
\end{array}\right.
$$

Thin elastohydrodynamic films in the meshing teeth pairs of gears at high load are often subjected to non-Newtonian shear behaviour. Evans and Johnson [28] reported an analyticalexperimental expression for viscous friction under these conditions, taking into account the effect of heat generated in the contact as:

$f_{v}=W_{h}\left(0.87 \alpha \tau_{0}+1.74 \frac{\tau_{0}}{\bar{p}} \ln \left(\frac{1.2}{\tau_{0} h_{c 0}}\left(\frac{2 \dot{K} \eta_{0}}{1+9.6 \zeta}\right)^{1 / 2}\right)\right)$

where:

$\zeta=\frac{4}{\pi} \frac{\dot{K}}{h_{c 0} / R_{z x}}\left(\frac{\bar{p}}{E^{\prime} R_{Z x} K^{\prime} \rho^{\prime} c^{\prime} U}\right)^{1 / 2}$

Therefore, the total friction becomes:

$f=f_{v}+f_{b}$

\section{Starved contacts and inlet boundary condition}

The results presented in figure 3 correspond to an assumed fully flooded inlet. However, realistic inlet boundary conditions should be used in the analysis. The results of both the numerical analysis and those predicted by Chittenden's extrapolated oil film thickness formula should, therefore, be adjusted for this purpose. One approach is to determine a demarcation boundary ahead of the contact inlet where a fully flooded inlet may be assumed. A starvation boundary parameter was defined through numerical analysis by Hamrock and Dowson [24] and experimentally through optical interferometric studies by Wedeven et al [38]. These were defined as:

Hamrock and Dowson [24]: $\quad m^{*}=1+3.06\left[(R / \gamma)^{2} h_{c 0}\right]^{0.58}$

Wedeven et al [38]: $\quad m^{*}=1+3.52\left[(R / \gamma)^{2} h_{c 0}\right]^{2 / 3}$ 
where, for the flow component along the minor axis: $R=R_{z x}, \gamma=b^{\prime}$, and for that along the major axis: $R=R_{z y}, \gamma=a^{\prime}$. The actual inlet distance, $m$, is obtained according to a calculated inlet boundary condition (see later). If $m<m^{*}$, then the central film thickness should be adjusted in order to take into account the effect of starvation as [24]:

$\left(\frac{h_{c 0, S}}{h_{c 0, F}}\right)=\left(\frac{m-1}{m^{*}-1}\right)^{0.29}$

\section{Inlet boundary condition}

Tipei [25] found that in the inlet zone there are swirl flows, where some reverse flow (counter flow) occurs. This is also noted in experimental observations by Birkhoff and Hays [38]. It means that only a fraction of the inlet lubricant flow is admitted into the contact domain. This is another reason for starvation. The physical inlet, $m$ is the distance to the centre of the contact footprint from the centre of the counter flow region (the point of zero reverse flow). Comparing this inlet distance with the starvation boundary in either equations (21) and (22) determines the extent of contact starvation.

Tipei's method is based on the potential flows in the inlet region $\left(Q_{1}, Q_{2}, Q_{3}\right)$ in figure 4 . Applying the compatibility condition yields [25]:

$$
\begin{aligned}
& \cot ^{2} \pi\left[\frac{1}{2}-\frac{1-k}{f(k)}\right]-\cot ^{2} \pi \sqrt{\left[\frac{1}{2}-\frac{1-k}{f(k)}\right]^{2}-\frac{2 k}{f(k)}}=\cot \pi\left\{\frac{1}{2}-\frac{1-k}{f(k)}-\sqrt{\left[\frac{1}{2}-\frac{1-k}{f(k)}\right]^{2}-\frac{2 k}{f(k)}}\right\} \times \\
& \cot \pi\left\{\frac{1}{2}-\frac{1-k}{f(k)}+\sqrt{\left[\frac{1}{2}-\frac{1-k}{f(k)}\right]^{2}-\frac{2 k}{f(k)}}\right\}
\end{aligned}
$$

where:

$k=\frac{U_{1}}{U_{2}}$ (ratio of surface speeds of the contiguous solids)

and $f(k)$ is a function of the pressure gradient in a converging gap. At the inlet point $\mathrm{A}$ in figure 4, $\frac{d p}{d \theta_{i}} \propto k$. Thus for the aforementioned inlet flow rates $\left(Q_{1}, Q_{2}, Q_{3}\right)$ :

$$
2(1+\sqrt{k})^{2} \leq f(k) \leq 6(1+\sqrt{k})
$$


Values of $f(k)$ for some usually encountered cases of $k$ are listed in table 1.

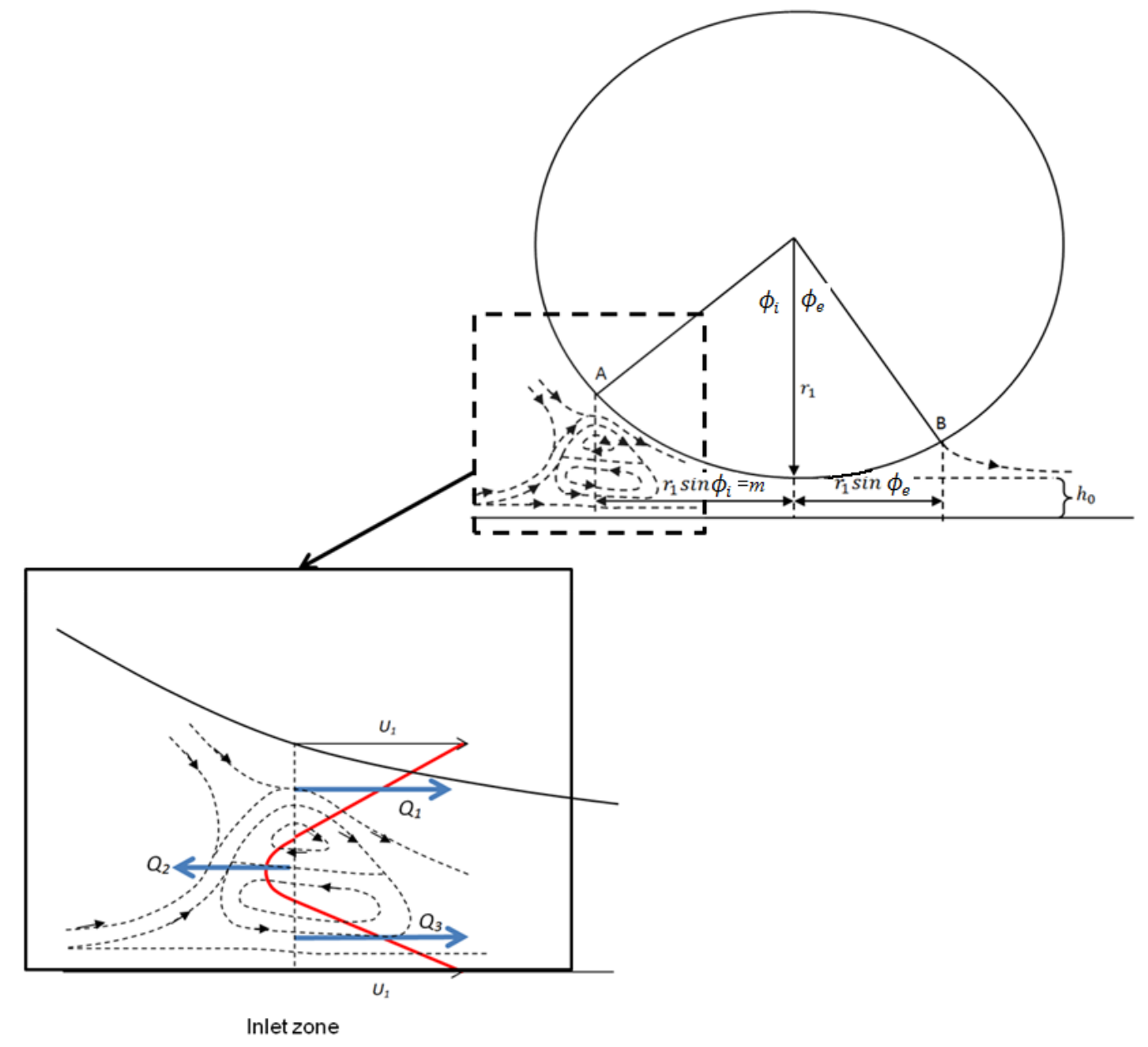

Figure 4: Flow through contact carried by the solid surfaces

Table 1: calculated values for $f(k)$

\begin{tabular}{|c|c|}
\hline$k$ & $f(k)$ \\
\hline 0 & 4 \\
\hline 0.5 & 7.8 \\
\hline 1 & $32 / 2$ \\
\hline
\end{tabular}

Prandtl-Hopkins boundary conditions do not allow the observed swirl flow at the inlet [26]. Thus, Tipei [25] used the Swift-Stieber condition at the inlet, hence:

$\cos \phi_{i}=-\left[1-\frac{h_{c 0}}{R_{z x}}\left(\cosh \vartheta_{i}-1\right)\right]$ 
where the dimensionless term $\vartheta_{i}$ is the ratio of film thickness at the inlet to the minimum film thickness $\left(h_{i} / h_{c 0}\right.$ ). Similarly the $\vartheta_{e} \underline{\text { can be defined for the exit boundary. These are obtained }}$ as:

$\frac{\cosh \vartheta_{i}}{\cosh \vartheta_{e}}=\frac{1-\frac{1}{3}\left(1+\frac{2 \sqrt{k}}{1+k}\right)}{1-\frac{f(k)}{6(1+k)}}$

and:

$$
\begin{aligned}
{\left[1-\frac{1}{3}\left(1+\frac{2 \sqrt{k}}{1+k}\right)\right] \tanh \vartheta_{e} } & -\left[1+\frac{f(k)}{6(1+k)}\right] \tanh \vartheta_{i} \\
- & {\left[1-\frac{f(k)}{6(1+k)}\right] \cosh \vartheta_{i}\left[\arcsin \left(\tanh \vartheta_{e}\right)-\arcsin \left(\tanh \vartheta_{i}\right)\right]=0 }
\end{aligned}
$$

The physical inlet distance $m$ is thus found from the solution of equations (26)-(29) (see figure 4) as:

$m=R_{z x} \sin \phi_{i}$

Figure 5 shows the zero reverse inlet boundary (the actual inlet distance) $m$ using the above method for a complete typical meshing cycle at vehicle speed of $20 \mathrm{Km} / \mathrm{h}$. The figure also shows the starvation inlet boundary for the same condition. It can be seen that the actual calculated) inlet is well within the starvation zone. 


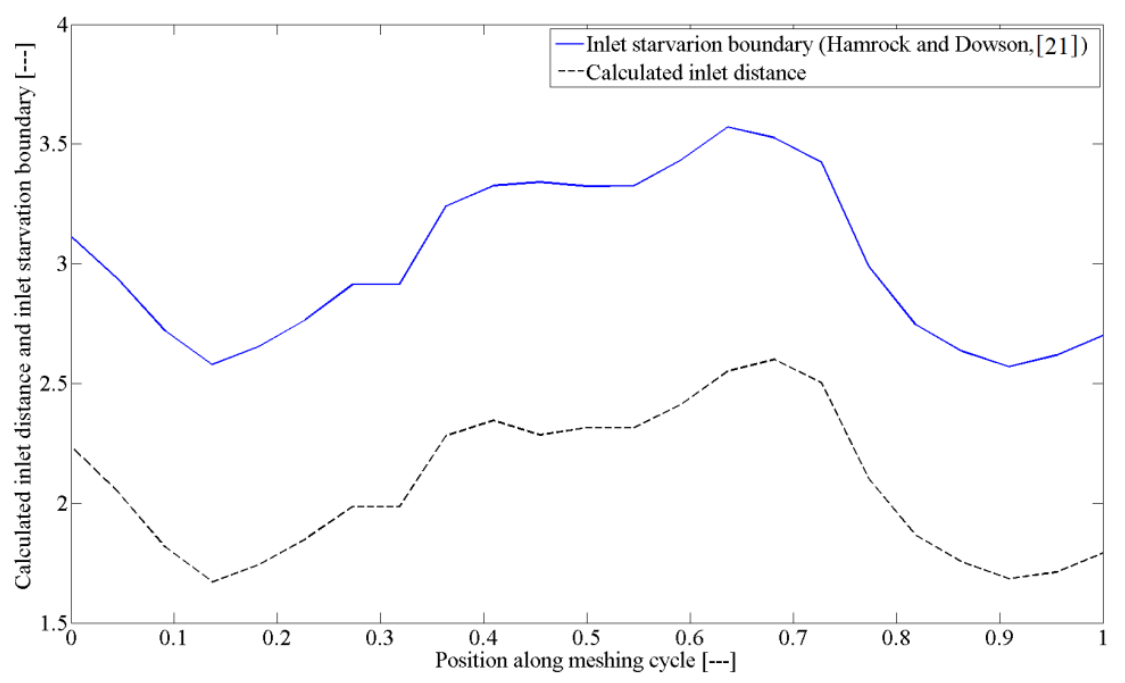

Figure 5: Inlet starvation threshold $\left(\mathrm{m}^{*}\right)$ and the calculated inlet distance $m$ at $20 \mathrm{~km} / \mathrm{h}$

\section{Gear pair dynamics}

The gear dynamic model comprises a two-degrees-of-freedom torsional system. The governing equations of motion are given below, where the indices $p$ and $g$ refer to the pinion and gear respectively. The same methodology has been used and described in detail in $[1,39$, 40]. Unlike parallel axes gear pairs, due to the complex geometry of hypoid gears, it is not possible to calculate the meshing stiffness, radii of curvature and contact kinematics using simple approximation methods. Therefore, the meshing stiffness variation with respect to pinion angle $k_{m}\left(\varphi_{p}\right)$ has been calculated using TCA [6]. A damping ratio of 0.003 has been used for the calculation of the damping coefficient, $c_{m}$. This is in line with low fluid film damping noted in $[16,17]$. Hence:

$I_{p} \ddot{\varphi}_{p}+R_{p} c_{m} \dot{X}+R_{p} k_{m}\left(\varphi_{p}\right) f(X)=T_{p}+T_{f r, p}$

and:

$I_{w} \ddot{\varphi}_{w}-R_{w} c_{m} \dot{X}-R_{w} k_{m}\left(\varphi_{w}\right) f(X)=-T_{w}+T_{f r, w}$

The backlash non-linearity is defined as:

$f(X)= \begin{cases}X-b, & X \geq b \\ 0, & -b<X<b \\ X+b, & X \leq-b\end{cases}$ 
where, $X$ denotes the teeth relative displacement along the instantaneous line of approach of a pair of teeth: $X(t)=\int_{0}^{t} R_{p} \dot{\varphi_{p}} d t-\int_{0}^{t} R_{w} \dot{\varphi_{w}} d t-e(t)$

$e(t)$ is the unloaded static transmission error obtained through TCA and expressed as a Fourier function of time [39, 40].

The applied forces and torques to the differential gearing and the vehicle model are obtained as [41]:

$T_{w}=r_{\text {Wheel }} \Sigma F$

where $r_{\text {wheel }}$ is the laden wheel radius and $\Sigma F$ is the net tractive force. This is obtained by considering the vehicle longitudinal dynamics on a flat terrain as:

$\Sigma F=R_{a}+R_{r l}=M a$

Under steady vehicle speed $V$ (as is the case in this analysis) $a=0$, and the resistive components yielding tractive forces acting on the driving wheels are [41]:

$R_{a}=\frac{\rho}{2} C_{D} A_{f} V^{2}$

$R_{r l}=f_{r l} W_{v}$

Where [41]:

$f_{r l}=0.01\left(1+\frac{V}{147}\right)$

The input torque to the differential pinion includes the sinusoidal variation in engine torque (engine order vibration). For a 4-stroke 4-cylinder engine (subject of this analysis), the main engine order vibration is twice the crankshaft speed with a $10 \%$ oscillatory contribution [42]:

$T_{p}=\frac{R_{p}}{R_{w}} T_{w}\left(1+0.1 \cos \left(2 R_{t} A_{p} t\right)\right)$

where: $\omega=R_{t} A_{p}$ 
The frictional torque in gear teeth meshing is thus obtained as:

$\left\{\begin{array}{c}T_{f r, p}=R_{p} f \\ T_{f r, w}=R_{w} f\end{array}\right.$

\section{Results and Discussion}

The hypoid gear pair of a commercial vehicle differential with a 4-cylinder 4-stroke diesel engine is considered in the current analysis. The gear data are listed in Table A1 in Appendix A2. Table A2 lists the vehicle data, which provides the resisting torque on the differential ring gear side at any speed. Required rheological data and thermal properties of lubricant are listed in Table A3.

For the tribological analysis, there is a need to determine the dynamic loads per meshing teeth pairs at any instant of time. This is obtained through the solution of dynamics equation of motion (31) and (32) for the gear pair, using all the forces from vehicle longitudinal dynamics as well as from the lubricated contacts. Thus, the link between vehicle dynamics and instantaneous contact conditions is established. The instantaneous solution is obtained through application of Runga-Kutta step-by-step integration in time steps of $10 \mu \mathrm{s}$. The load share per meshing teeth pair is then determined, using [39, 40]:

If $=\frac{F_{i}}{\sum F}$

where, $l f$ is the ratio of the applied load $F_{i}$ on a given flank under consideration to the total transmitted load $\sum F$.

Figure 6-a shows the dynamic meshing load per teeth pair for the simulated conditions. This is an essential input from the gear pair dynamics for use in lubricated contact ana;ysis. The quasi-static load is also provided on this figure. There is a significant difference between the dynamic load generated as the result of vehicle tractive motion an inertial gear dynamics and the usually used quasi-static analysis. This difference affects the generated contact pressure distribution and shear stress distribution and consequently changes the viscous shear damping. 


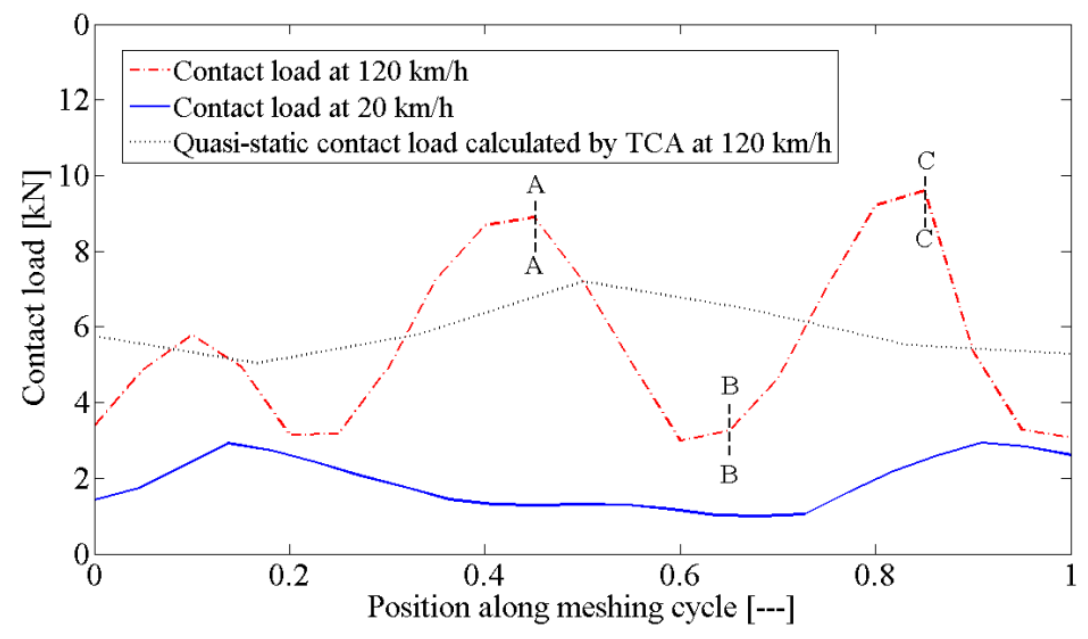

Figure 6-a: Transient contact load for typical meshing teeth pair

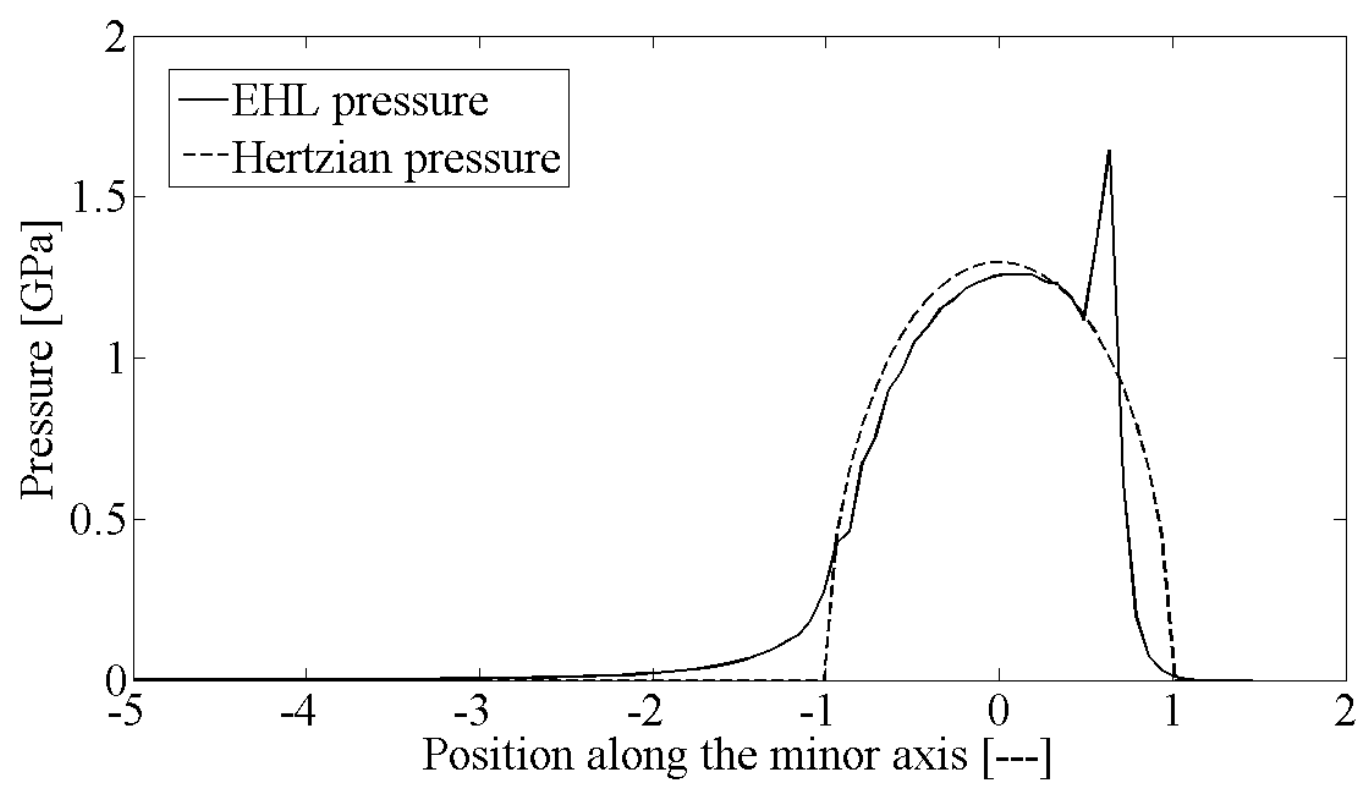

Section A-A of Fig. 6-a 


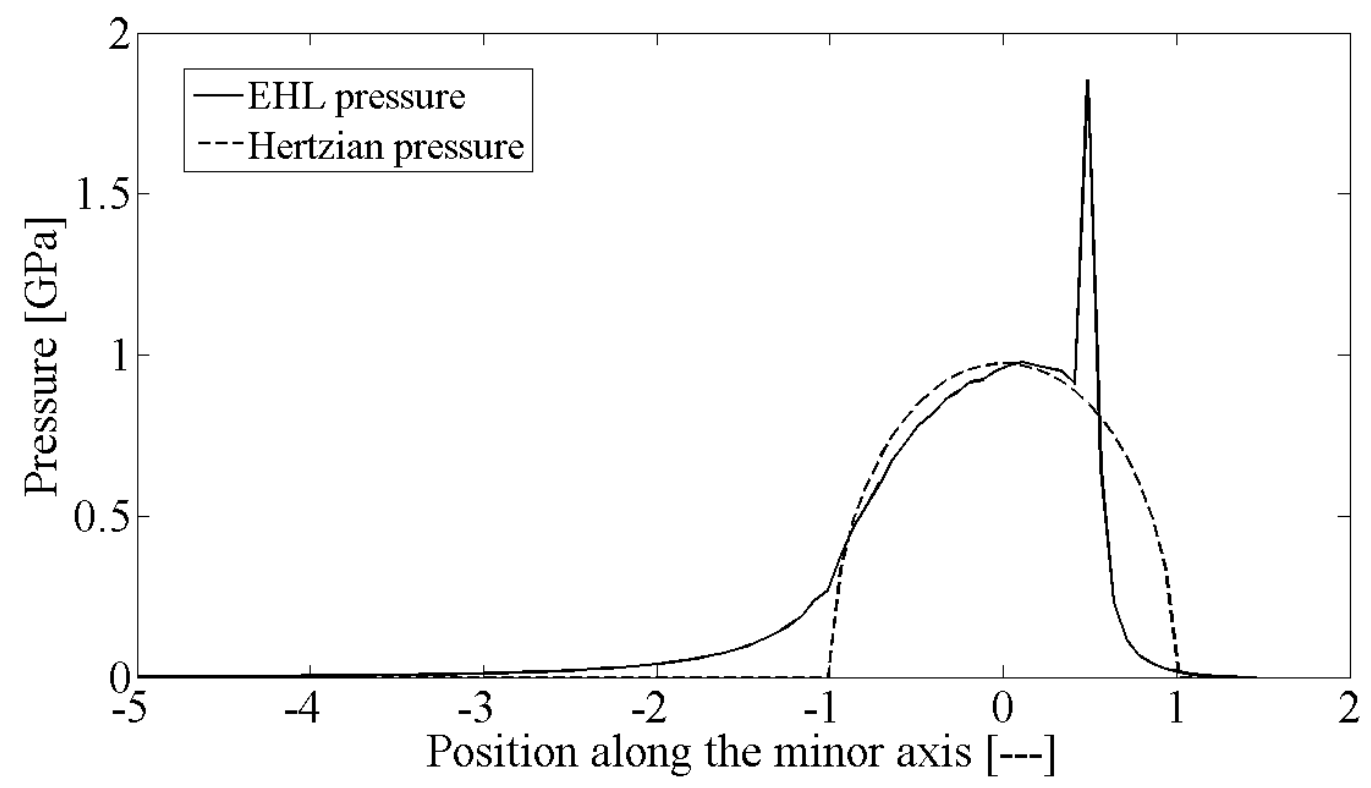

Section B-B of fig. 6-a

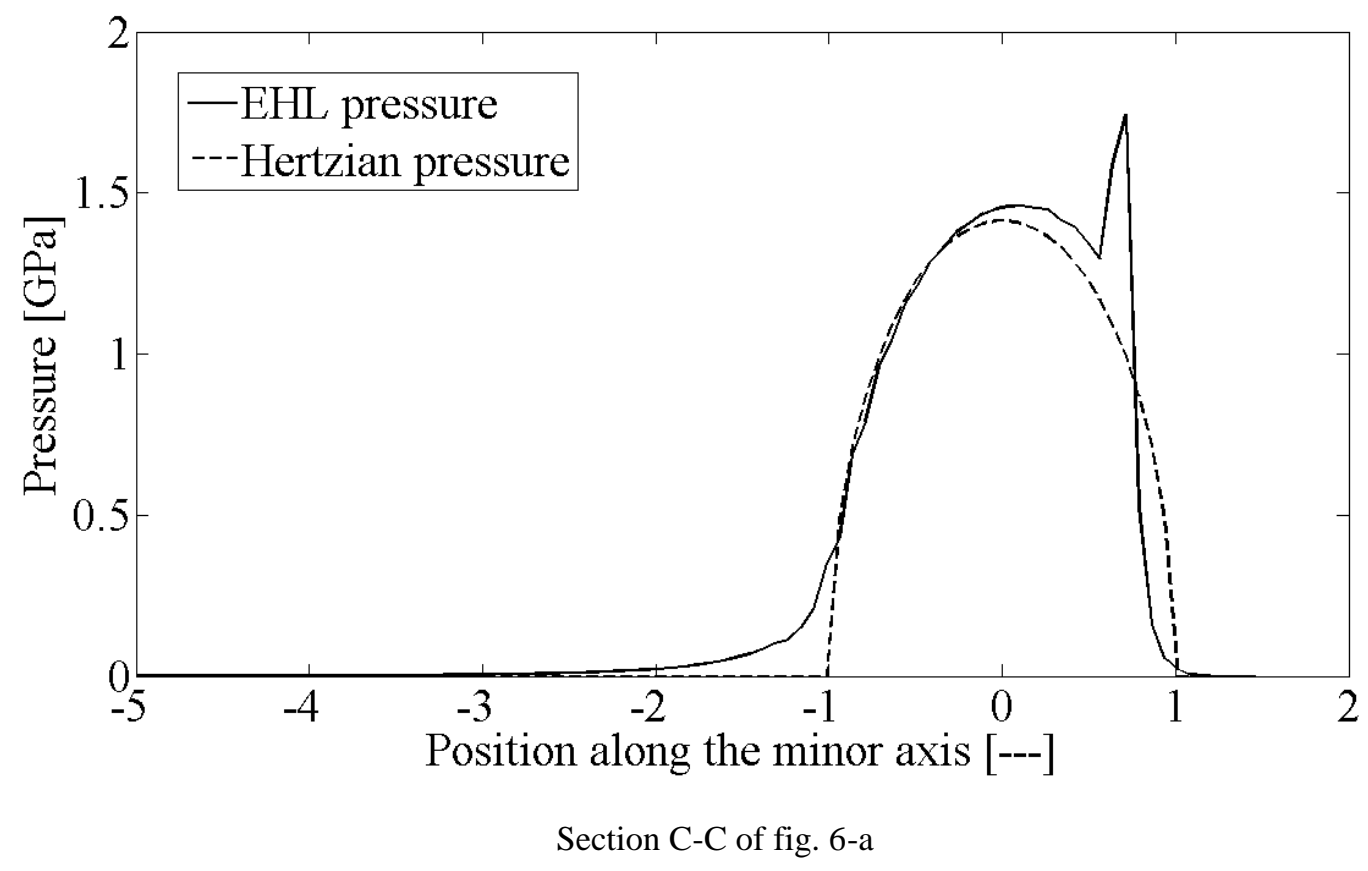

Figure 6-b: Elastohydrodynamic pressure distributions for different sections of figure 6-a.

Figures 6-b shows a series of elastohydrodynamic pressure distributions along the minor axis of the contact ellipse at sections marked in figure 6-a. These results show a significant fluctuations in the generated contact pressures which follow the transient nature of the applied load. The dry Hertzian pressure profile is also shown in each case.

An important point to note is the larger variation in the contact load at higher vehicle speed, 
constituting a greater degree of NVH. This can be explained by higher peak-to-peak dynamic transmission error (DTE) values that can lead in greater contact pressure fluctuations and therefore higher induced noise. The DTE time history is shown in figure 7.

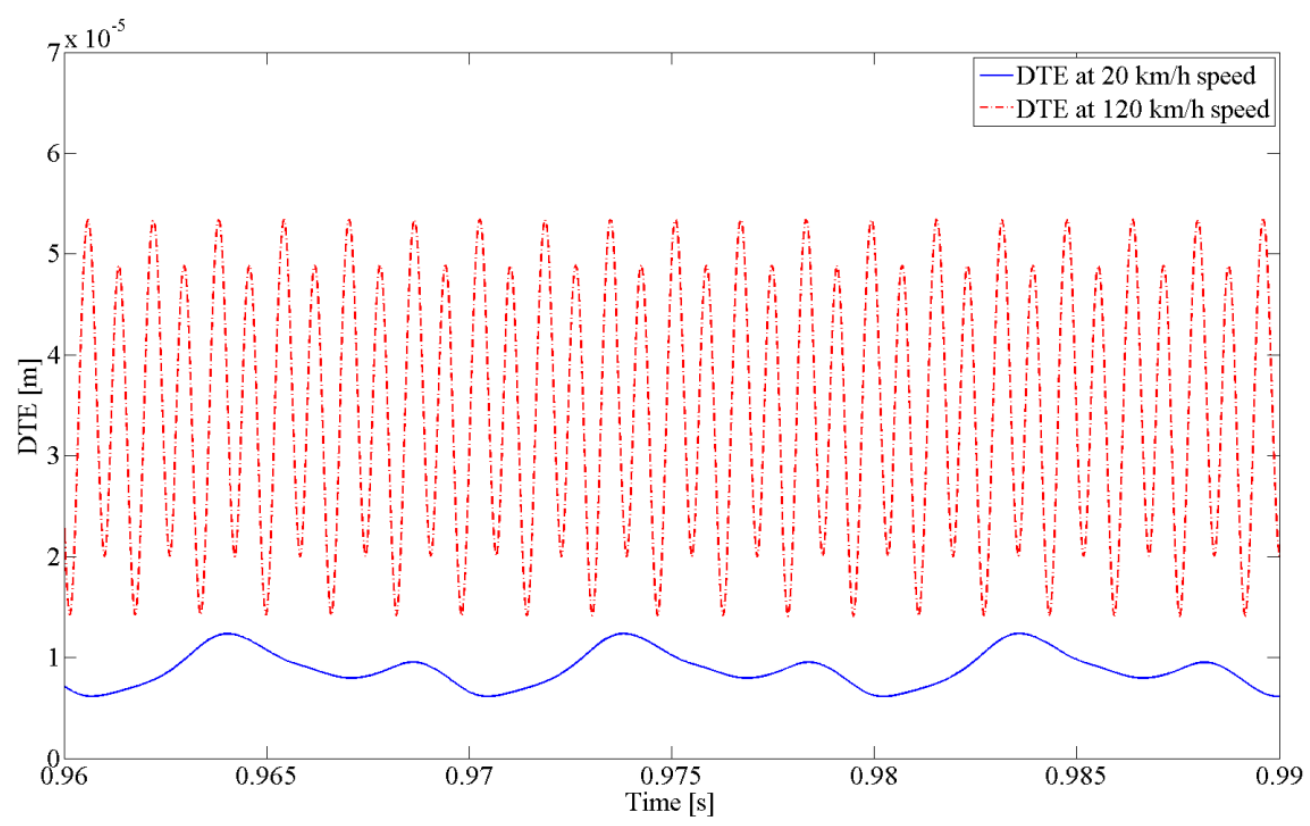

Figure 7: DTE at $20 \mathrm{~km} / \mathrm{h}$ and $120 \mathrm{~km} / \mathrm{h}$.

Figures 8 and 9 illustrate the variation of film thickness during a meshing cycle predicted by numerical analysis using Reynolds equation, as well as by the Chittenden's extrapolated oil film thickness formula at different speeds. In both cases fully flooded inlet conditions are assumed. Additionally, the results obtained using the extrapolated formula adjusted for the physically determined zero-reverse inlet boundary, are also presented. All the curves show the instantaneous film thickness values during a meshing cycle. The abscissa determines the position along the meshing cycle from the start of the meshing of a pair of teeth to the end of mesh, where the teeth separate. Two vehicle speeds are used; one at $20 \mathrm{~km} / \mathrm{h}$ (figure 8), representing the low speed urban driving condition and the other at $120 \mathrm{~km} / \mathrm{h}$ (figure 9) which is typical of highway driving. All the necessary data for the analyses are provided in the appendix 2. Both figures show that when the realistic inlet boundary condition is employed the film thickness is consistently thinner than that usually predicted assuming an idealised fully flooded inlet. 


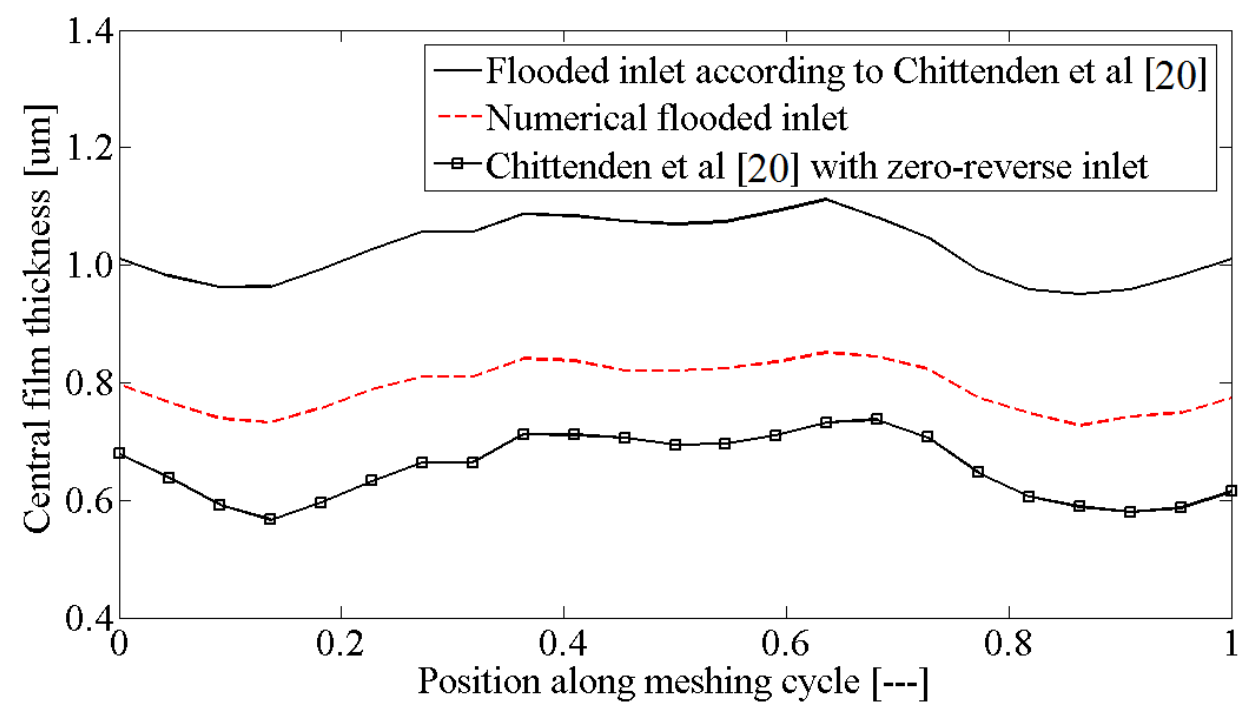

Figure 8: Film thickness values at $20 \mathrm{~km} / \mathrm{h}$ during one meshing cycle

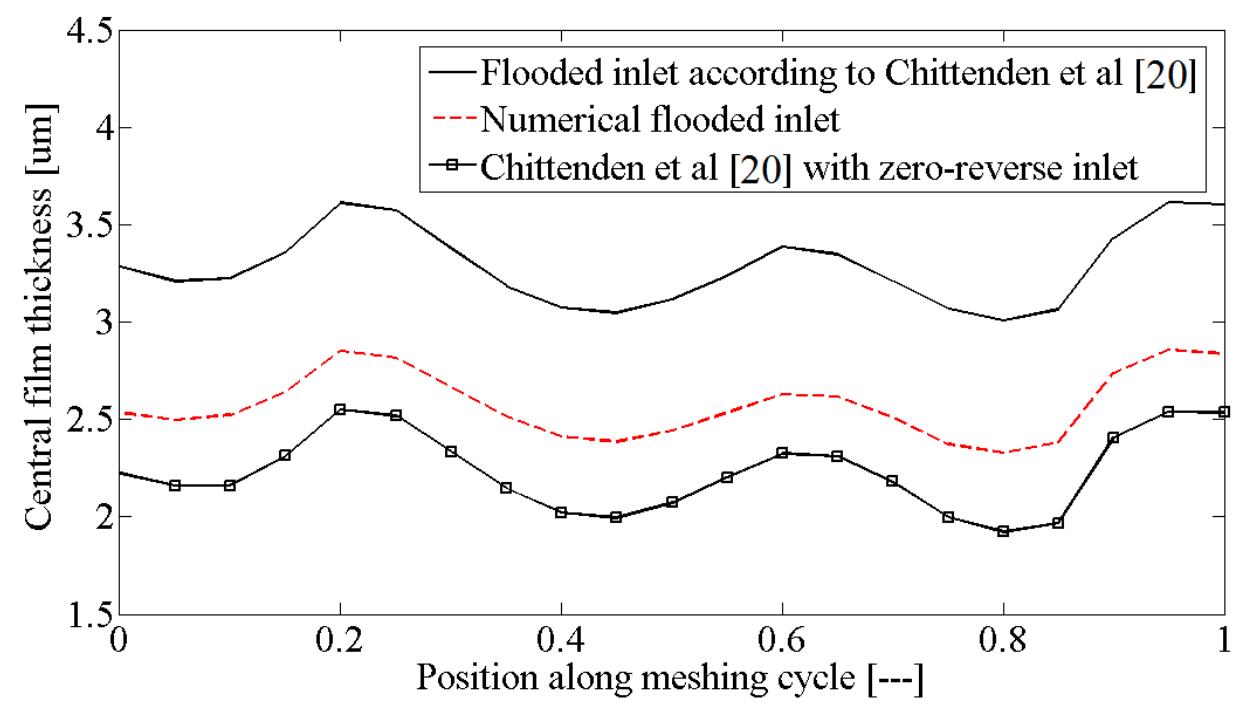

Figure 9: Film thickness values at $120 \mathrm{~km} / \mathrm{h}$ during one meshing cycle

One of the main concerns in transmission engineering is the generated conjunctional friction. Figure 10 shows the total friction, $f$, at the vehicle speeds of 20 and $120 \mathrm{~km} / \mathrm{h}$. These results are based on the starved lubricant film thickness in figures 8 and 9 and adjustment for nonNewtonian shear, taking into account the effect of contact generated heat as embodied in equation (18). Figure 11 shows the position of one meshing cycle on the traction map provided in [28]. It shows that the lubricant continually undergoes transitions between Newtonian and non-Newtonian traction under the operating conditions.

Friction is greater at the higher vehicle speed, because of an increased rate of lubricant shear, although the film thickness is reduced at the lower speed due to diminished entrainment. 
There is, however, a higher chance of boundary friction at the lower vehicle speed. This is corroborated by the results in figure 12 . However, it is interesting to note that the contribution of boundary friction to the overall friction is fairly small (around 2\%). This is as the result of the fairly smooth honed gear surfaces in the current analysis. Since contact friction is the main source of energy dissipation in the absence of any significant fluid film damping under elastohydrodynamic regime of lubrication $[16,17]$, the reduced friction constitutes a greater residual excess energy which causes a higher vibratory response, as can be seen in figure 6 .



Figure 10: Generated total friction

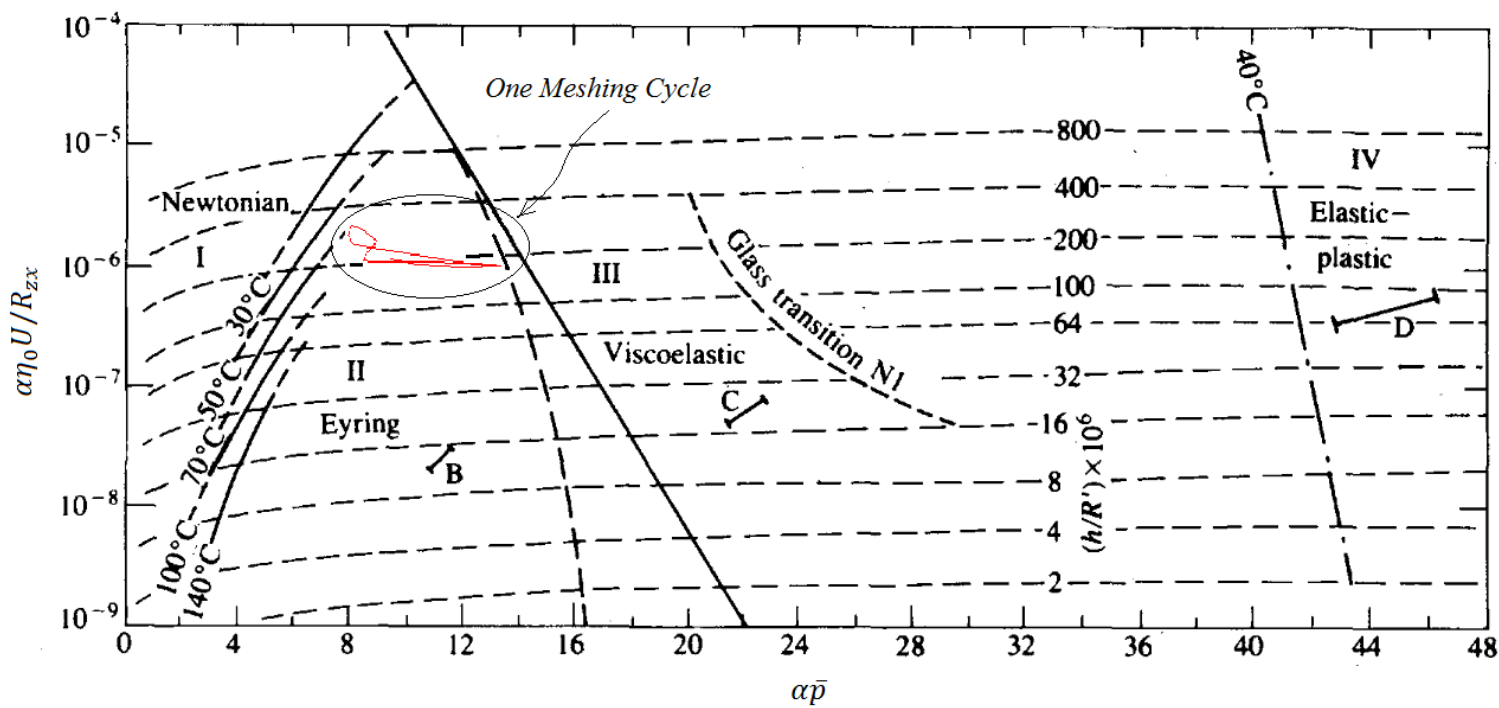

Figure 11: Locus of lubricant tractive behaviour in a meshing cycle at $20 \mathrm{~km} / \mathrm{h}$ plotted on the traction map of Evans and Johnson [28] 


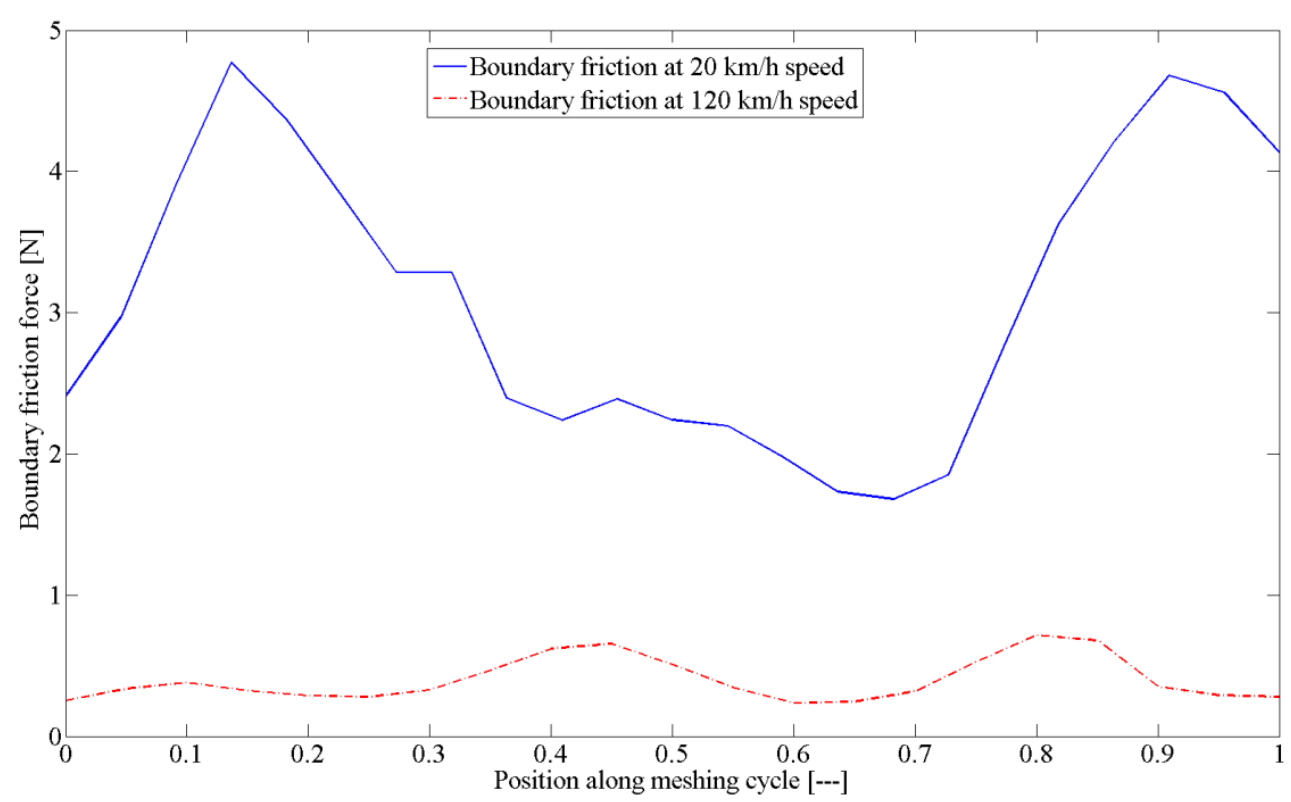

Figure 12: Boundary friction contribution

Figure 13 shows the variation of fuel consumption during a meshing cycle. It shows that the higher speed yields greater fuel consumption due to increased shear. The power loss per meshing teeth is calculated as: $P_{f j}=f_{j} \Delta u_{j}$, where $\Delta u_{j}$ is the sliding velocity of teeth pair $j$. Efficiency is defined as: $\%$ Efficiency $=\left(\frac{T_{p} \dot{\varphi}_{p}-\sum_{j} f_{j} \Delta u_{j}}{T_{p} \dot{\varphi}_{p}}\right) \times 100$. Figure 14 presents the differential efficiency during the meshing cycle, where $j$ pairs of teeth are in simultaneous mesh. It shows that unlike friction and fuel consumption, there is better efficiency at higher speeds. Note that transmission efficiency is a function of tribo-dynamics (tribology and dynamics) of the system rather than the usually presumed purely tribological attribute. 


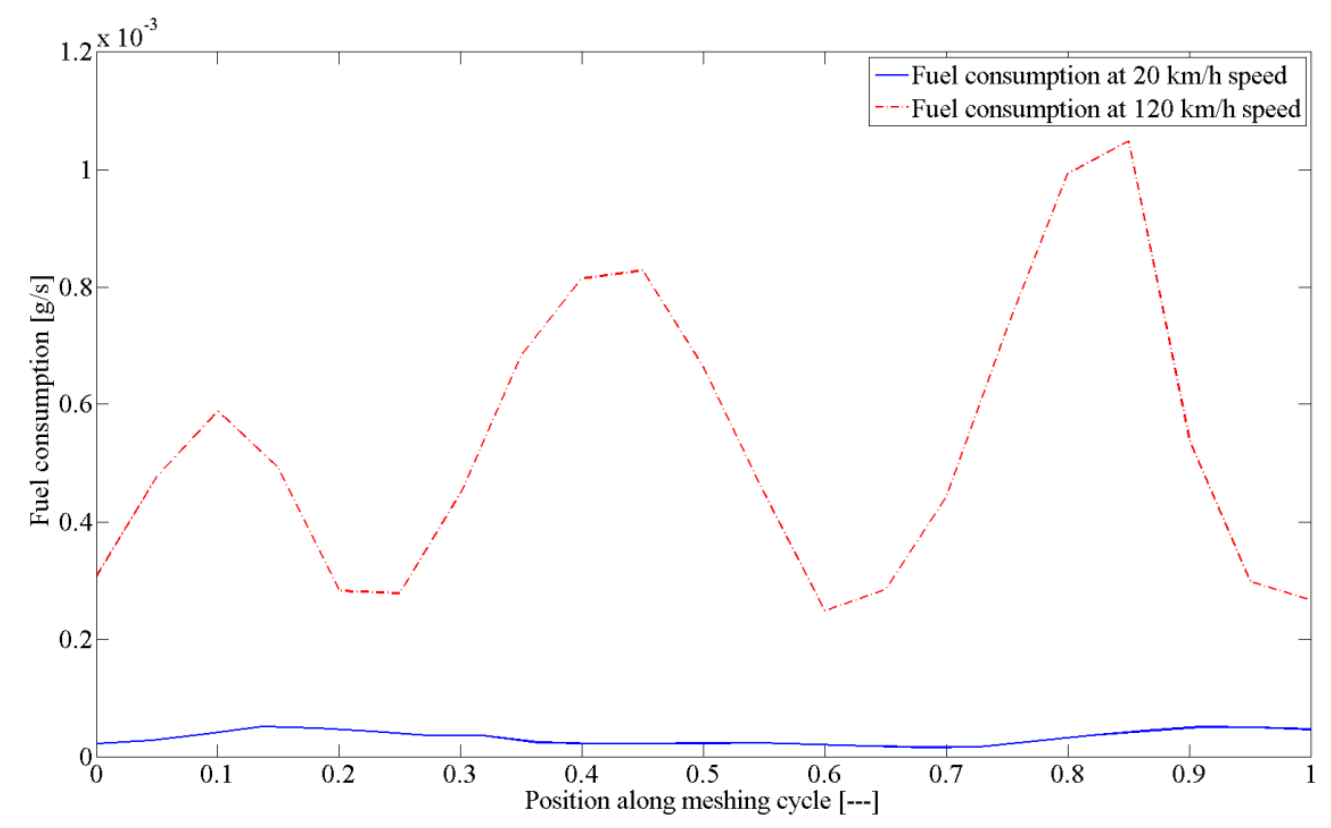

Figure 13:. Fuel consumption during meshing cycle at different speeds

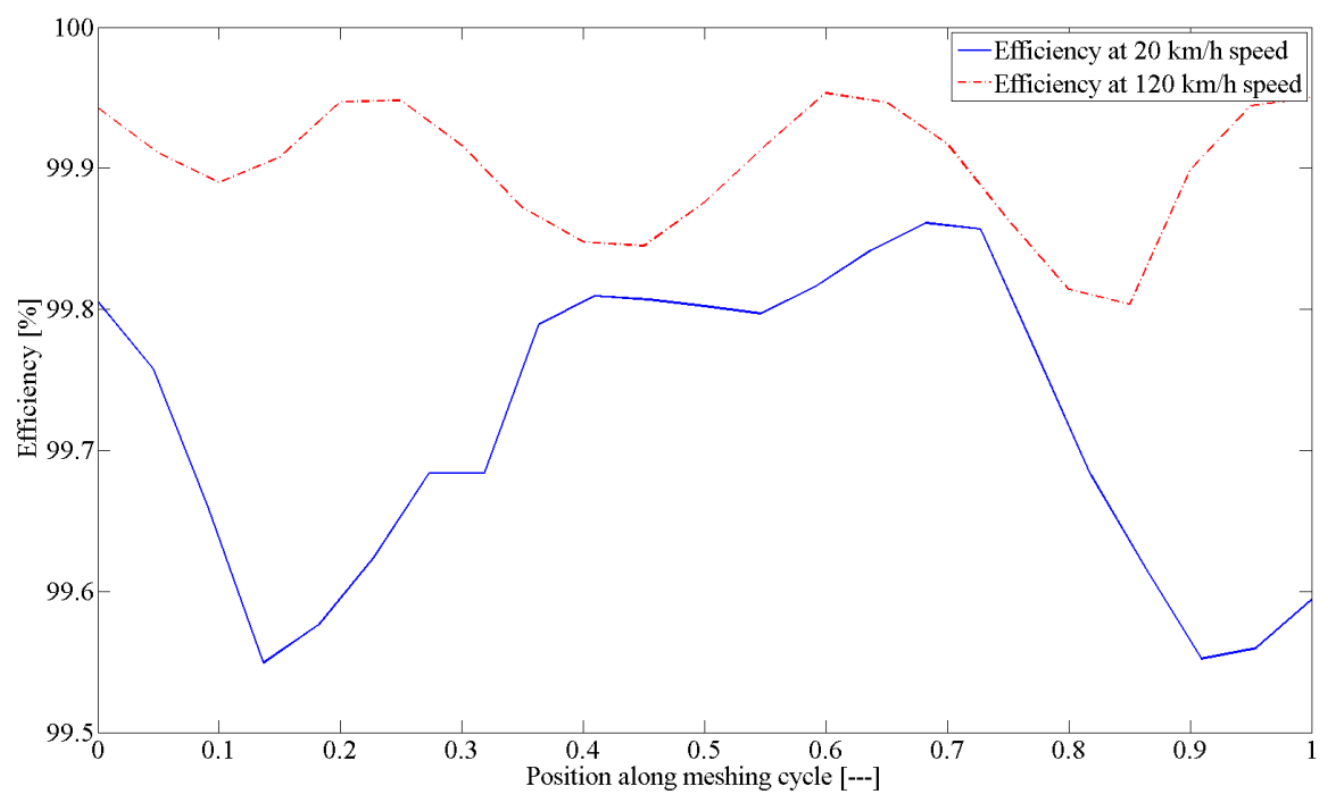

Figure 14: Transmission efficiency during a meshing cycle

\section{Concluding Remarks}

A key conclusion of the presented results is the link between instantaneous tribological contact conditions, dynamics of meshing differential hypoid gear pairs and vehicle dynamics in longitudinal manoeuvre. The analysis also shows that the meshing pairs run under starved conditions in mixed elastohydrodynamic regime of lubrication with thin films subjected to 
non-Newtonian shear. The complex nature of transmission engineering is also clear from the paradoxical relationship between transmission efficiency (optimum at high vehicle speeds) and NVH (optimum at lower vehicle speed). The link between these attributes is in fact friction. Lower friction constitutes the reduction of an energy sink which consumes the excess energy provided by high output power modern engines, therefore exacerbating vibratory response. In the case of differentials, this excess energy can lead to global elastic deformation waves which excited structural modes of progressively lighter and more elastic lightly damped powertrain and chassis components. Differential axle whine is only one of such growing concerns [43]. The future direction of this research is to incorporate the highlighted methods in a flexible multi-body combined powertrain and chassis model.

\section{Acknowledgement}

The authors wish to acknowledge the financial support of Wolfson School Scholarship Fund and technical support of Ford Motor Company.

\section{Nomenclature}

A Contact apparent area

$A_{a} \quad$ Asperity area

$A_{f} \quad$ Vehicle frontal area

$A_{p} \quad$ Pinion angle

a Acceleration

$a^{\prime} \quad$ Contact semi-major half-width

$b \quad$ Half of teeth pair backlash

$b^{\prime} \quad$ Contact semi-minor half-width

$C_{D} \quad$ Drag coefficient

$c_{m} \quad$ Damping coefficient in the direction of mesh

$c^{\prime} \quad$ Thermal coefficient of bounding solid surfaces 
$E_{r} \quad$ Reduced elastic modulus: $E_{r}=\frac{\pi}{\left[1-v_{p}^{2} / E_{p}\right]+\left[1-v_{w}^{2} / E_{w}\right]}$

$E_{w}, E_{p}$ Young's modulus of gear and pinion material

$E^{\prime} \quad E_{r} / \pi$

F Traction

f Total friction

$f_{b} \quad$ Boundary friction

$f_{v} \quad$ Viscous friction

$f_{r l} \quad$ Coefficient of rolling resistance

$h \quad$ Central contact film thickness

$h_{c 0} \quad$ Central contact film thickness

$\underline{h}_{c 0, S}$ Central contact film thickness, starved

$\underline{h_{c 0, F}}$ Central contact film thickness, fully flooded

$h^{*} \quad$ Dimensionless film thickness

$I_{p}, I_{w} \quad$ Mass moments of inertia of pinion and gear

$\dot{K} \quad$ Thermal conductivity of the lubricant

$K^{\prime} \quad$ Thermal conductivity of the solids

$k \quad$ Speed ratio

$k_{m} \quad$ Mesh stiffness

$M \quad$ Vehicle mass

$m \quad$ Inlet boundary parameter

$m^{*} \quad$ Starvation demarcation boundary parameter

$\bar{p} \quad$ Average pressure

$p \quad$ Pressure 
$p_{m} \quad$ Mean pressure

$R_{z x} \quad$ Equivalent radius of contact along the minor axis

$R_{z y} \quad$ Equivalent radius of contact along the major axis

$R_{p}, R_{w}$ Pinion and gear contact radii

$R_{a} \quad$ Aerodynamic resistance

$R_{r l} \quad$ Rolling resistance

$R_{t} \quad$ Transmission ratio

$r_{\text {Wheel }}$ Tyre radius

$T_{p}, T_{w}$ Externally applied torques to the pinion and gear

$T_{f r, p}, T_{f r, w}$ Frictional moments at pinion and gear

$U \quad$ Speed of entraining motion

$V \quad$ Vehicle speed

W Contact load

$W_{a} \quad$ Asperity load

$W_{h} \quad$ Hydrodynamic load

$W_{v} \quad$ Vehicle weight

$X \quad$ teeth relative displacement along the instantaneous line of approach

$x \quad$ Direction/distance along the minor axis of the elliptical footprint

$y \quad$ Direction/distance along the major axis of the elliptical footprint

\section{Greek symbols}

$\alpha \quad$ Lubricant pressure-viscosity coefficient

$\beta \quad$ Average asperity tip radius

$\delta \quad$ Local elastic deflection

$\varepsilon \quad$ Slope of the lubricant limiting shear stress-pressure dependence 
$\eta \quad$ Lubricant dynamic viscosity

$\eta_{0} \quad$ Inlet lubricant dynamic viscosity

$\theta \quad$ Angle of lubricant entrainment into the contact

$\underline{\vartheta_{i}} \quad$ Ration of film thickness at inlet to the minimum film thickness $h_{i} / h_{c 0}$

$\underline{\vartheta}_{e} \quad$ Ration of film thickness at exit to the minimum film thickness $h_{e} / h_{c 0}$

$\lambda \quad$ Stribeck's oil film parameter

$\xi \quad$ Asperity density per unit area

$\rho^{\prime} \quad$ Density of solids

$\rho \quad$ Density of lubricant

$\rho_{0} \quad$ Inlet density of lubricant

$\sigma \quad$ Composite RMS surface roughness $\left(\sigma=\sqrt{\sigma_{1}^{2}+\sigma_{2}^{2}}\right)$

$\sigma_{1} \quad$ Bearing surface roughness $\mathrm{Ra}$

$\sigma_{2} \quad$ Journal surface roughness $\mathrm{Ra}$

$\tau_{0} \quad$ Eyring shear stress

$\tau_{L} \quad$ Limiting shear stressType equation here.

$v_{p} \quad$ Poisson's ratio for the pinion gear material

$v_{w} \quad$ Poisson's ratio for the gear wheel material

$\varphi_{p}, \varphi_{w}$ Pinion and gear angle of rotation

$\phi_{i} \quad$ Inlet position angle

$\phi_{e} \quad$ Exit position angle

$\omega \quad$ Engine frequency 


\section{References}

[1]- Mohammadpour, M., Theodossiades, S., Rahnejat, H. and Kelly, P. "Transmission efficiency and NVH refinement of differential hypoid gear pairs", Proc. IMechE, Part K: Journal of Multi-body Dynamics, 2013, doi: 10.1177/1464419313496559

[2]- Kolivand, M. and Kahraman, A. "A load distribution model for hypoid gears using easeoff topography and shell theory", Mechanism \& Machine Theory, 2009, 44, pp. 1848-1865

[3]- $\mathrm{Xu}, \mathrm{H}$. and Kahraman, A. "Prediction of friction-related power losses of hypoid gear pairs", Proc. IMechE, J. Multi-body Dyn., 2007, 221, pp. 387-400

[4]- Cheng, Y. and Lim, T.C., "Vibration analysis of hypoid transmission applying an exact geometry based gear mesh theory", Journal of Sound and Vibration, 2001, 240(3), pp. 519543

[5]- Wang, J., Lim, T.C. and Li, M., "Dynamics of a hypoid gear pair considering the effects of time-varying mesh parameters and backlash nonlinearity", Journal of Sound and Vibration, 2007, 229(2), pp.287-310.

[6]- Mohammadpour, M. Theodossiades, S. and Rahnejat, H. "Elastohydrodynamic lubrication of hypoid gears at high loads", Proc. IMechE., Part J: J. Engineering Tribology, 2012,226

[7]- Mohammad-Pour, M., Theodossiades, S. and Rahnejat, H. "Elastohydrodynamics of Hypoid Gears in Axle Whine Conditions", SAE Technical Paper 2012-01-1538, 2012, 011538, doi:10.4271/2012-01-1538

[8]-Vijayakar S, (2000) CALYX Manual. Advanced Numerical Solutions Inc., Columbus, Ohio, 2000

[9] Li, S. and Kahraman, A., "Influence of Dynamic Behavior on Elastohydrodynamic Lubrication of Spur Gears," Journal of Engineering Tribology, 225, 740-753, 2011.

[10] Li, S. and Kahraman, A., "A Spur Gear Mesh Interface Damping Model Based on Elastohydrodynamic Contact Behavior," International Journal of Powertrains, 1 (1), 4-21, 2011.

[11] Li, S. and Kahraman, A. "A Tribo-dynamic Model of a Spur Gear Pair," Journal of Sound and Vibration, 332(20), 4963-4978, 2013.

[12]- Gohar, R. and Rahnejat, H., "Fundamentals of Tribology", Imperial College Press, 2008, ISBN- 13 978-1-84816-184-9

[13]- Chippa, S.P. and Sarangi, M., "On the Dynamics of Lubricated Cylindrical Roller Bearings, Part I: Evaluation of Stiffness and Damping Characteristics", Trib. Transactions, 56(6), 2013, pp. 1087-1096 
[14]- R. Brancati, E. Rocca, R. Russo, "A gear rattle model accounting for oil squeeze between the meshing gear teeth", Proc. IMechE, Part D: J. Automobile Engineering, 219, 2005, pp. 1075-1083.

[15]- Tangasawi, O., Theodossiades, S. and Rahnejat, H., Lightly loaded lubricated impacts: Idle gear rattle", Journal of Sound and Vibration, 308(3), 2007, pp. 418-430

[16]- D. W. Dareing and K. L. Johnson, Fluid film damping of rolling contact vibrations, J. Eng. Sci., 17 (4), 1975, pp. 214 - 219.

[17]- Mehdigoli, H., Rahnejat, H. and Gohar, R. "Vibration response of wavy surfaced disc in elastohydrodynamic rolling contact”, Wear, 139(1), 1990, pp. 1-15

[18]- Lankarani, H.M. and Nikravesh, P.E., A Contact Force Model With Hysteresis Damping for Impact Analysis of Multibody Systems, J. Mech. Des., 112(3), 369-376 (Sep 01, 1990) (8 pages)

[19]- Rahnejat, H. and Gohar, R., "The vibrations of radial ball bearings", Proc. IMechE, Part C: J. Mech. Eng. Sci., 199(3), 1985, pp. 181-193

[20]- De la Cruz, M., Theodossiades, S., King, P. and Rahnejat, H. Transmission drive rattle with thermo-elastohydrodynamic impacts: Numerical and experimental investigations. International Journal of Powertrains, 2011, 1(2), 137-161.

[21]- Thorp, N. and Gohar, R., "Hydrodynamic friction in elliptical and circular point contacts", Trans. ASME, J. Lubrication Technol., 94, 1971, pp. 199-208

[22]- Jalali-Vahid, D., Rahnejat, H., Gohar, R. and Jin, Z.M., "Prediction of oil-film thickness and shape in elliptical point contacts under combined rolling and sliding motion", Proc. IMechE, J. Engineering Tribology, 214(5), 2000, pp. 427-437

[23]- Chittenden, R. J., Dowson, D., Dunn, J. F. and Taylor, C. M. "A theoretical analysis of the isothermal elastohydrodynamic lubrication of concentrated contacts. II. General Case, with lubricant entrainment along either principal axis of the Hertzian contact ellipse or at some intermediate angle“", Proc. Roy. Soc., Ser. A, 397, 1985, pp. 271-294

[24]- Hamrock, B.J. and Dowson, D. "Isothermal elastohydrodynamic lubrication of point contacts, Part IV - Starvation results", Trans. ASME, J. Lubn. Tech., 99, 1977, pp. 15-23

[25]- Tipei, N., "Boundary Conditions of a Viscous Flow Between Surfaces With Rolling and Sliding Motion”, Trans. ASME, J. Lubn. Tech.., 90(1), 1968, 8 pp.

[26]- Mohammadpour, M., P. M. Johns-Rahnejat, H. Rahnejat, and R. Gohar. "Boundary Conditions for Elastohydrodynamics of Circular Point Contacts", Tribology Letters, 2013, pp. 1-12. DOI: 10.1007/s11249-013-0249-0

[27]- Mohammadpour, M., S. Theodossiades, H. Rahnejat, and T. Saunders. "Non-Newtonian mixed elastohydrodynamics of differential hypoid gears at High Loads." Meccanica, 2013, DOI 10.1007/s11012-013-9857-X 
[28]- Evans, C. R. and Johnson, K. L. "Regimes of traction in elastohydrodynamic lubrication”, Proc. IMechE, J. Mech. Eng. Sci., 200 (C5), 1986, pp. 313-324

[29]- Yang, P., Cui, J., Jin, Z. M., Dowson, D.,” Transient elastohydrodynamic analysis of elliptical contacts. Part 2: thermal and Newtonian lubricant solution", Proc. IMechE, Part J: J. Engineering Tribology, 2005, 219, 187-200

[30]- Roeland, C.J.A., Correlation aspect of the viscosity-temperature-pressure relation of lubrication oils, PhD Thesis, Delft University of Technology, The Netherlands, 1966

[31]- Dowson, D. and Higginson, G.R. "A numerical solution to the elastohydrodynamic problem”, Proc. IMechE, J. Mech. Eng. Sci., 1, 15, pp. 6-15

[32]- Hamrock, B.J. and Dowson, D. "Isothermal elastohydrodynamic lubrication of point contacts, Part I - Theoretical formulation”, Trans. ASME, J. Lubn. Tech., 98, 176, pp. 223229

[33]- Jalali-Vahid, D., Rahnejat, H., Jin, Z. M., Dowson, D., "Transient analysis of isothermal elastohydrodynamic circular point contacts." Proc. IMechE, Part C: J. Mechanical Engineering Science, 215(10), 2001, pp. 1159-1172.

[34]- Greenwood J. A, and Tripp J. H, "The contact of two nominally flat rough surfaces", Proc. Instn. Mech. Engrs, 185, 1970, pp. 625-633

[35]- Mohammadpour, M., Rahmani, R. and Rahnejat, H.," Effect of cylinder deactivation on the tribo-dynamics and acoustic emission of overlay big end bearings." Proc. IMechE, Part K: J. Multi-body Dynamics, 2013, in print queue

[36]- Briscoe, B. J., and Evans, D. C. B. (1982). The shear properties of Langmuir-Blodgett layers. Proc. Roy. Soc., Series A. Mathematical and Physical Sciences, 380(1779), 1982, pp. 389-407.

[37]- Wedeven, L.D., Evans, D. and Cameron, A. "Optical analysis of ball bearing starvation", Trans. ASME, J. Lubn. Tech., 93, 1971, pp. 349-363

[38]- Birkhoff, G., and Hays, D., "Free Boundaries in Partial Lubrication," J. Math. and Phys., 42 (2), June1963

[39]- Karagiannis, I., Theodossiades, S. and Rahnejat, H., "On the dynamics of lubricated hypoid gears", Mechanism and Machine theory, 48, 2012, pp. 94-120

[40]- Karagiannis, I. and Theodossiades, S., "An Alternative Formulation of the Dynamic Transmission Error to Study the Oscillations of Automotive Hypoid Gears", Journal of Vibration and Acoustics 136(1), 011001, doi:10.1115/1.4025206

[41]- Gillespie, T. D., "Fundamentals of Vehicle Dynamics", Society of Automotive Engineering, Inc. Pa, USA, 1992

[42]- Rahnejat, H., "Multi-body dynamics: Vehicles, Machines and Mechanisms", Professional Engineering Publishing (IMechE), Bury St Edmunds, 1998, ISBN 0768002699 
[43]- Koronias, G., Theodossiades, S., Rahnejat, H. and Saunders, T., "Axle whine phenomenon in light trucks: a combined numerical and experimental investigation", Proc. IMechE, Part D: J. Automobile Engineering, 225(7), 2011, pp. 885-894

\section{Appendix A1:}

The non-dimensional form of Reynolds equation becomes:

$$
\frac{\partial}{\partial \mathrm{X}}\left[\frac{\bar{\rho} \mathrm{H}^{3}}{\bar{\eta}} \frac{\partial \mathrm{P}}{\partial \mathrm{x}}\right]+\frac{1}{\mathrm{~K}^{2}} \frac{\partial}{\partial \mathrm{Y}}\left[\frac{\bar{\rho} \mathrm{H}^{3}}{\bar{\eta}} \frac{\partial \mathrm{P}}{\partial \mathrm{y}}\right]=\psi\left\{\cos \theta \frac{\partial}{\partial \mathrm{X}}[\bar{\rho} \mathrm{H}]+\frac{1}{\bar{K}} \sin \theta \frac{\partial}{\partial \mathrm{Y}}[\bar{\rho} \mathrm{H}]\right\}
$$

where, the following dimensionless groups are used:

$\psi=\frac{12 U \eta_{0} R_{\mathrm{Zx}}^{2}}{P_{\max } b^{3}}, \mathrm{X}=\frac{\mathrm{x}}{\mathrm{a}}, \mathrm{Y}=\frac{\mathrm{y}}{\mathrm{b}}, \bar{\rho}=\frac{\rho}{\rho_{0}}, \bar{\eta}=\frac{\eta}{\eta_{0}}, \mathrm{H}=\frac{\mathrm{hR}_{\mathrm{zx}}}{\mathrm{a}^{2}}, \mathrm{P}=\frac{\mathrm{P}}{\mathrm{P}_{\max }}, \bar{K}=\frac{b}{a}$

The discretized form of Reynolds equation is obtained as:

$$
\begin{aligned}
& \frac{1}{2 \Delta X^{2}}\left\{\left[\left(\frac{\bar{\rho} H^{3}}{\bar{\eta}}\right)_{i, j}+\left(\frac{\bar{\rho} H^{3}}{\bar{\eta}}\right)_{i-1, j}\right] P_{i-1, j}-\left[\left(\frac{\bar{\rho} H^{3}}{\bar{\eta}}\right)_{i+1, j}+2\left(\frac{\bar{\rho} H^{3}}{\bar{\eta}}\right)_{i, j}+\left(\frac{\bar{\rho} H^{3}}{\bar{\eta}}\right)_{i-1, j}\right] P_{i, j}+\right. \\
& \left.\left[\left(\frac{\bar{\rho} H^{3}}{\bar{\eta}}\right)_{i+1, j}+\left(\frac{\bar{\rho} H^{3}}{\bar{\eta}}\right)_{i, j}\right] P_{i+1, j}\right\}+\frac{1}{2 \bar{K} \Delta Y^{2}}\left\{\left[\left(\frac{\bar{\rho} H^{3}}{\bar{\eta}}\right)_{i, j}+\left(\frac{\bar{\rho} H^{3}}{\bar{\eta}}\right)_{i, j-1}\right] P_{i, j-1}-\left[\left(\frac{\bar{\rho} H^{3}}{\bar{\eta}}\right)_{i, j+1}+2\left(\frac{\bar{\rho} H^{3}}{\bar{\eta}}\right)_{i, j}+\right.\right. \\
& \left.\left.\left(\frac{\bar{\rho} H^{3}}{\bar{\eta}}\right)_{i, j-1}\right]_{i, j}+\left[\left(\frac{\bar{\rho} H^{3}}{\bar{\eta}}\right)_{i+1, j}+\left(\frac{\bar{\rho} H^{3}}{\bar{\eta}}\right)_{i, j}\right] P_{i+1, j}\right\}-\frac{\psi \cos \theta}{\Delta X}\left[(\bar{\rho} H)_{i+1, j}+(\bar{\rho} H)_{i, j}\right]-\frac{\psi \sin \theta}{\bar{K} \Delta Y}\left[(\bar{\rho} H)_{i, j+1}+(\bar{\rho} H)_{i, j}\right]- \\
& \frac{b \bar{\rho}}{u_{a v} R_{x}}\left(\frac{d H}{d \bar{t}}\right)_{i, j}=0
\end{aligned}
$$


Table A1: Gear pair parameters

\begin{tabular}{|c|c|c|}
\hline Parameter & Pinion & Gear \\
\hline Number of teeth & 13 & 36 \\
\hline face-width $(\mathrm{mm})$ & 33.851 & 29.999 \\
\hline face angle $\left(^{\circ}\right)$ & 29.056 & 59.653 \\
\hline pitch angle $\left(^{\circ}\right)$ & 29.056 & 59.653 \\
\hline root angle $\left(^{\circ}\right)$ & 29.056 & 59.653 \\
\hline spiral angle $\left(^{\circ}\right)$ & 45.989 & 27.601 \\
\hline pitch apex $(\mathrm{mm})$ & -9.085 & 8.987 \\
\hline face apex $(\mathrm{mm})$ & 1.368 & 10.948 \\
\hline Outer cone distance $(\mathrm{mm})$ & 83.084 & 95.598 \\
\hline offset $(\mathrm{mm})$ & 24.0000028 & 24 \\
\hline Hand & Right & Left \\
\hline
\end{tabular}

Table A2: Analysis conditions

\begin{tabular}{|c|c|}
\hline Parameter & Value \\
\hline$A_{f}$ (frontal area) & $3.42 \mathrm{~m}^{2}$ \\
\hline$f_{r l}$ (rolling resistance coefficient) & 0.0166 \\
\hline$C_{D}$ (drag coefficient) & 1.15 \\
\hline$\rho$ (air density) & $1.22 \mathrm{~kg} / \mathrm{m}^{3}$ \\
\hline$W_{v}$ (vehicle weight) & $2340 \mathrm{~kg}$ \\
\hline Tyre & P205/65R $15 \mathrm{BSW}$ \\
\hline 2nd gear ratio & $1.5: 1$ \\
\hline Surface Roughness of solids & $1.2 \mu \mathrm{m}$ \\
\hline
\end{tabular}


Table A3: Lubricant and solids properties

\begin{tabular}{|c|c|}
\hline Pressure viscosity coefficient $(\alpha)$ & $2.3827 \mathrm{E}-008\left[\mathrm{~Pa}^{-1}\right]$ \\
\hline Atmospheric dynamic viscosity at $40^{\circ} \mathrm{C}\left(\eta_{0}\right)$ & $0.19514[\mathrm{~Pa} . \mathrm{s}]$ \\
\hline Eyring stress $\tau_{0}$ & $2[\mathrm{MPa}]$ \\
\hline Pressure-induced shear coefficient $(\varepsilon)$ & 0.047 \\
\hline Thermal conductivity of fluid & $0.14[\mathrm{~J} / \mathrm{kgK}]$ \\
\hline Heat capacity of fluid & $2000[\mathrm{~W} / \mathrm{mK}]$ \\
\hline Modulus of elasticity of contacting solids & $210[\mathrm{GPa}]$ \\
\hline Poisson's ratio of contacting solids & $0.3[-]$ \\
\hline Density of contacting solids & $7850[\mathrm{~kg} / \mathrm{m} 3]$ \\
\hline Thermal conductivity of contacting solids & $46[\mathrm{~W} / \mathrm{mK}]$ \\
\hline Heat capacity of contacting solids & $470[\mathrm{~J} / \mathrm{kgK}]$ \\
\hline
\end{tabular}

